\title{
The microRNAs as potential biomarkers for predicting the onset of aflatoxin exposure in human beings: a review
}

\author{
Rafael Valencia-Quintana ${ }^{1}{ }^{*}$, Juana Sánchez-Alarcón ${ }^{1}$, María G. Tenorio-Arvide ${ }^{2}$, Youjun Deng $^{3}$, \\ José M. R. Montiel-González', Sandra Gómez-Arroyo ${ }^{4}$, Rafael Villalobos-Pietriní, \\ Josefina Cortés-Eslava ${ }^{4}$, Ana R. Flores-Márquez ${ }^{4}$ and Francisco Arenas-Huertero ${ }^{5 *}$ \\ Evaluación de Riesgos Ambientales, Facultad de Agrobiología, Universidad Autónoma de Tlaxcala, Tlaxcala, México \\ ${ }^{2}$ Departamento de Investigación en Ciencias Agrícolas, Benemérita Universidad Autónoma de Puebla, Puebla, México \\ ${ }^{3}$ Department of Soil and Crop Sciences, Texas AgriLife, Texas A\&M University, College Station, TX, USA \\ ${ }^{4}$ Departamento de Ciencias Ambientales, Centro de Ciencias de la Atmósfera, Universidad Nacional Autónoma de México, Distrito Federal, México \\ ${ }^{5}$ Laboratorio de Patología Experimental, Hospital Infantil de México Federico Gómez, Distrito Federal, México
}

Edited by:

Mehdi Razzaghi-Abyaneh, Pasteur

Institute of Iran, Iran

Reviewed by:

Eva-Guadalupe Lizárraga-Paulín, Universidad Nacional Autónoma de México, Mexico

Jing Shen, Columbia University, USA

\section{*Correspondence}

Rafael Valencia-Quintana, Evaluación de Riesgos Ambientales, Facultad de Agrobiología, Universidad Autónoma de Tlaxcala, Av. Universidad No.1, Col. La Loma Xicohténcatl, 90070 Tlaxcala de Xicohténcatl, Tlaxcala, México e-mail:prvq2004@yahoo.com.mx; Francisco Arenas-Huertero, Laboratorio de Patología

Experimental, Hospital Infantil de México Federico Gómez,

Dr. Márquez 162, Col. Doctores, 06720 Ciudad de México, Distrito

Federal, México

e-mail: farenashuertero@

yahoo.com.mx
The identification of aflatoxins as human carcinogens has stimulated extensive research efforts, which continue to the present, to assess potential health hazards resulting from contamination of the human food supply and to minimize exposure. The use of biomarkers that are mechanistically supported by toxicological studies will be important tools for identifying stages in the progression of development of the health effects of environmental agents. miRNAs are small non-coding mRNAs that regulate post-transcriptional gene expression. Also, they are molecular markers of cellular responses to various chemical agents. Growing evidence has demonstrated that environmental chemicals can induce changes in miRNA expression. miRNAs are good biomarkers because they are well defined, chemically uniform, restricted to a manageable number of species, and stable in cells and in the circulation. miRNAs have been used as serological markers of HCC and other tumors. The expression patterns of different miRNAs can distinguish among HCC-hepatitis viruses related, HCC cirrhosis-derivate, and HCC unrelated to either of them. The main objective of this review is to find unreported miRNAs in $\mathrm{HCC}$ related to other causes, so that they can be used as specific molecular biomarkers in populations exposed to aflatoxins and as early markers of exposure, damage/presence of HCC. Until today specific miRNAs as markers for aflatoxins-exposure and their reliability are currently lacking. Based on their elucidated mechanisms of action, potential miRNAs that could serve as possible markers of $\mathrm{HCC}$ by exposure to aflatoxins are miR-27a, miR-27b, miR-122, miR-148, miR-155, miR-192, miR-214, miR-221, miR-429, and miR-500. Future validation for all of these miRNAs will be needed to assess their prognostic significance and confirm their relationship with the induction of HCC due to aflatoxin exposure.

Keywords: AFB1, aflatoxin exposure, microRNAs, HCC, potential biomarkers

\section{INTRODUCTION}

The aflatoxins were structurally identified in the early 1960s and over the last 50 years have been extensively studied with respect to their mechanisms of action, including their mutagenic and carcinogenic activity. This work has been paralleled by developments in biomarkers of aflatoxin metabolism, DNA adducts, and mutations applied to exposed human populations. The improvements in exposure assessment in epidemiological studies and the demonstration of a specific mutation in the TP53 gene have contributed significantly to the identification of aflatoxins as human carcinogens. In addition, the studies of animal and human aflatoxin metabolism have provided opportunities to develop chemoprevention approaches in human populations (Wild and Turner, 2002; Valencia-Quintana et al., 2012). These findings stimulated extensive research efforts, which continue to the present, to assess potential health hazards resulting from contamination of the human food supply and to minimize exposure (Kensler et al., 2011).

The use of biomarkers that are mechanistically supported by toxicological studies will be important tools for identifying stages in the progression of development of the health effects of environmental agents. Since the development of a general paradigm for molecular epidemiology and biomarkers nearly 20 years ago, progress has been made in applying these tools to specific environmental situations that may be hazardous to humans, as exemplified by AFB1 studies. The major goals of molecular epidemiology research are to develop and to validate biomarkers that reflect specific exposures, their interactions, and predictions of disease risk in individuals. Presumably, after an environmental exposure each person has a unique response to both dose 
and time to disease onset. These responses will be affected both by genetic, host and environmental modifiers. It is assumed that biomarkers that reflect the mechanisms of action of the etiologic agents will be strong predictors of an individual's risk of disease. It is also expected that these biomarkers can more clearly classify the status of exposure of individuals and general populations (Groopman et al., 2005).

Biomarkers can be used as outcome measures in these and primary prevention studies. Overall, the integrated, multidisciplinary research on aflatoxins has provided the scientific platform on which to base decisions regarding acceptable exposures and priorities for interventions to reduce human risk in a public health context (Wild and Turner, 2002).

\section{AFLATOXIN BIOMARKERS}

AFB1 requires metabolic activation to its ultimate carcinogenic form, a reactive epoxide (aflatoxin-8,9-epoxide), primarily by the cytochrome P450 (CYP) monooxygenase system. Epoxidation is catalyzed by CYP1A2 and CYP3A4 in humans (Gallagher et al., 1994; Ueng et al., 1995). Many other oxidation products, including aflatoxin $\mathrm{M} 1$, are also formed. The epoxide can react further by interacting with DNA to produce a promutagenic aflatoxinN7-guanine adduct. This adduct is unstable in DNA, rapidly undergoes depurination, and is excreted in urine (Bennett et al., 1981). The epoxide can also form products that react with serum albumin to form long-lived lysine adducts (Sabbioni et al., 1987). In addition, the epoxide can be conjugated by certain glutathione S-transferases (GSTs), which are further metabolized to form aflatoxin-mercapturic acid detoxification products that can be excreted in urine (Scholl et al., 1997). Urinary measures of aflatoxin M1, aflatoxin-mercapturic acid, and the aflatoxin-albumin adduct are used as biomarkers of internal dose. Aflatoxin-N7guanine in urine serves as an elegant biomarker of biologically effective dose because it is clear that formation of this adduct lies on the causal pathway to aflatoxin-induced HCC (Kensler et al., 2011).

An objective in development of AFB1 biomarkers is to use them as predictors of past and future exposure status in people (Kensler et al., 2011). However, two key attributes, one biological (tracking) and the other chemical (stability), need to be confirmed to successfully use biomarkers for these purposes. miRNAs are good biomarkers because they are well defined, chemically uniform, restricted to a manageable number of species, and stable in cells and in the circulation (Wang et al., 2012a).

\section{microRNAs AND ENVIRONMENTAL POLLUTANTS}

Exposure to environmental chemicals is well known to increase risks for various diseases (Crinnion, 2010; Newbold, 2010), and gene expression can be changed as a response to these exogenous stressors (Ueda, 2009; Patel and Butte, 2010; Hou et al., 2012), like tobacco and polycyclic aromatic hydrocarbons in urban air of megacities (Arenas-Huertero et al., 2011). Such changes may be regulated by specific miRNAs and emerged as a gene expression regulatory factor that may link environmental chemicals and their related diseases.

Secreted miRNAs have many requisite features of good biomarkers. miRNAs are stable in various bodily fluids, the sequences of most miRNAs are conserved among different species, the expression of some miRNAs is specific to tissues or biological stages, and the level of miRNAs can be easily assessed by various methods, as polymerase chain reaction (PCR), which allows for signal amplification. The changes of several miRNA levels in plasma, serum, urine, and saliva have already been associated with different diseases (for review see Etheridge et al., 2011).

Growing evidence has demonstrated that environmental chemicals can induce changes in miRNA expression (Hou et al., 2011). Arsenite exposure induced significant decrease in miR19a expression in human lymphoblast cells line TK-6, resulting in cell growth arrest and apoptosis (Marsit et al., 2006). Metal sulfates have been shown to generate reactive oxygen species (ROS) and trigger the expression of specific miRNAs (Lukiw and Pogue, 2007). Bollati et al. (2010) found an increased expression of miR-146a related to inhalation of Cd-rich air particles in steel workers, and induced rapid changes in the expression of two inflammation-related miRNAs, miR-21 and miR-222. Aluminum exposure may induce genotoxicity via miRNA-related regulatory elements, for example, miR-146a, miR-9, miR-125b, and miR-128 (Lukiw and Pogue, 2007; Pogue et al., 2009).

Jardim et al. (2009) have shown extensive alterations of miRNA expression profiles in human bronchial epithelial cells treated with diesel exhaust particles. Schembri et al. (2009) have identified 28 miRNAs that were differentially expressed in smokers when compared to non-smokers, changes in miRNA expression were suggested to contribute to altered regulation of oncogenes, tumor suppressor genes, oxidative stress, xenobiotic metabolism, and inflammation. Izzotti et al. (2009a,b) have monitored the expression of 484 miRNAs in the lungs of mice exposed to cigarette smoking, the most remarkably downregulated miRNAs belonged to several miRNA families, such as let-7, miR-10, miR-26, miR-30, miR-34, miR-99, miR-122, miR-123, miR-124, miR-125, miR-140, miR-145, miR-146, miR-191, miR-192, miR219, miR-222, and miR-223. These miRNAs regulate expression of genes involved in stress responses, apoptosis, proliferation, and angiogenesis.

Zhang and Pan (2009) have evaluated the effects of Hexahydro-1, 3, 5-trinitro-1, 3, 5-triazine (also known as hexogen or cyclonite) (RDX) on miRNA expression in mouse brain and liver, most of the miRNAs that showed altered expression, including let-7, miR-17-92, miR-10b, miR-15, miR-16, miR-26, and miR-181, were related to toxicant-metabolizing enzymes, and genes related to carcinogenesis, and neurotoxicity, in addition, consistent with the known neurotoxic effects of RDX, the authors documented significant changes in miRNA expression in the brains of RDX-treated animals, such as miR-206, miR-30a, miR30c, miR-30d, and miR-195. STS (sodium thiosulfate) treatment also resulted in differential expression of miR-124a and miR133a in the treated embryos (Choudhuri, 2010). Fukushima et al. (2007) have demonstrated that rat exposed to acetaminophen or carbon tetrachloride showed down-regulation of miR-298 and miR-370 in the liver that was accompanied by hepatocyte necrosis and inflammation. Wang et al. (2009a) found increase serum concentration of hepatocyte-specific miRNAs including miR122 and miR-192 within $1 \mathrm{~h}$ after acetaminophen exposure. In 
mouse exposure to $\mathrm{Wy}-14,643$, peroxisome proliferator-activated receptor alpha (PPAR $\alpha)$ agonist, up-regulate let-7C (Shah et al., 2007). Ethanol exposure down-regulate miR-21, miR-335, miR9, and miR-153 (Sathyan et al., 2007). In rats, tamoxifen upregulate miR-17-92 cluster, miR-106a, and miR-34 (Pogribny et al., 2007). 4-(methylnitrosamino)-1-(3-pyridyl)-1-butanone (NNK), a tobacco carcinogen, down-regulate miR-34, miR-101, miR-126, and miR-199 (Kalscheuer et al., 2008). In humans, 1 alpha, 25-dihydroxyvitamin $\mathrm{D}(3)$ [1,25(OH)(2) $\mathrm{D}(3)]$, major vitamin D metabolite, up-regulate miR-125b (Mohri et al., 2009), and 5-fluorouracil (5-FU) an antineoplasic drug, up-regulate miR-200b (Rossi et al., 2007). Bisphenol A (Avissar-Whiting et al., 2010), dioxin (Elyakim et al., 2010), and diethylstilbestrol (DES) (Hsu et al., 2009) desregulate expression of miR-146a, miR-191, and miR-9-3, respectively. Moffat et al. (2007) looked at the effects of dioxin treatment on miRNA in mice, dioxin-resistant rats (Han/Wistar; Kuopio) and dioxin-sensitive rats (Long-Evans; Turku/AB), it is interesting to note that the dioxin sensitive rats had more affected miRNAs. X-ray exposure resulted in down regulation of miR-7 (Ilnytskyy et al., 2008). The ROS induction resulted in up-regulation of a specific set of miRNAs, including miR-9, miR-125b, and miR-128 (Lukiw and Pogue, 2007). Lin et al. (2009), and Cheng et al. (2009), found that hydrogen peroxide induce up-regulation of miR- 21 .

The increasing evidence that the expression of miRNAs is affected by several known toxicants as well as oxidative and other forms of cellular stress certainly suggest an important role of miRNAs in toxicology, which could provide a link between environmental influences and gene expression (Lema and Cunningham, 2010). Analysis of the resulting molecular signatures provides new tools to identify mechanisms of toxicity, as well as to classify compounds based on the biological response they elicit and to identify cluster of genes detective or predictive of certain type of toxic response, which are employed as biomarkers (Gatzidou et al., 2007). miRNAs are one of the main mechanisms of epigenetic regulation of gene expression. Conversely to stress-related miRNAs, the toxicological research of miRNAs associated to specific toxicants has started few years ago. Therefore, available publications are focused in a broad spectra of toxicants and compiled research about a particular miRNA is yet very limited (Lema and Cunningham, 2010).

\section{microRNA IN HCC AS POTENTIAL BIOMARKERS OF AFLATOXIN EXPOSURE}

In the recent years, several studies revealed that the expression of miRNAs is deregulated in human HCC in comparison with matched non-neoplastic tissue (Lu et al., 2005; Gramantieri et al., 2008; Law and Wong, 2011; Borel et al., 2012a; Wang et al., 2012a,b; Sun and Karin, 2013; Wong et al., 2013). Some miRNAs identified in HCC are reported in Table $\mathbf{1 .}$

Cellular miRNAs can be released into the circulation, and circulating miRNA levels are also affected in HCC. Circulating plasma miRNA signatures may provide a novel diagnosis method for early, pre-symptomatic HCC patients, and may prove useful as prognosis biomarkers (Borel et al., 2012a).

In HCC has been reported up-expression of miR-21, miR-221, miR-22, miR-15, miR-517a, and down-expression of miR-122,
miR-29 family, miR-26a, miR-124, let-7 family members, and miR-199a/b-3p (Szabo et al., 2012). Other miR- reported as markers involved in HCC have been miR-15b, miR-16, miR-175p, miR-18, miR-18a, miR-20, miR-23b, miR-26a, miR-29, miR34a, miR-92, miR-101, miR-106a, miR-125b, miR-130b, miR-143, miR-146a, miR-195, miR-203, miR-223, miR-224, miR-338, miR378, miR-422b, miR-500 (Murakami et al., 2006; Budhu et al., 2008; Jiang et al., 2008; Chen, 2009; Zhang et al., 2009; Kerr et al., 2011; Qu et al., 2011; Liu et al., 2012; Singhal et al., 2012; Wong et al., 2013).

In a review, Gramantieri et al. (2008) show miRNAs aberrantly expressed in HCC compared to non-tumorous liver tissue (upexpression of miR-33, miR-130, miR-135a, miR-210, miR-213, miR-222, miR-331, miR-373, miR-376a, and down-expression of miR-130a, miR-132, miR-136, miR-139, miR-143, miR-145, miR150, miR-200a, miR-200b, miR-214). However, specific markers and their reliability are currently lacking as occur with aflatoxinexposure.

Singhal et al. (2012), review molecular and serum markers in HCC as predictive tools for prognosis and recurrence. Aberrant expression of miR-21 can contribute to HCC by modulating PTEN expression and PTEN-dependent pathways (Meng et al., 2007). A significantly high expression of miR-224 in HCC patients promotes proliferation and inhibits apoptosis inhibitor- 5 (API-5) transcript expression (Wang et al., 2008). An inverse correlation between miR-221 and both CDKN1B/p27 and CDKN1 $\mathrm{C} / \mathrm{p} 57$, suggested miR-221 oncogenic function in hepatocarcinogenesis (Fornari et al., 2008). Also miR-221 has been involved in the modulation of $\mathrm{Bmf}$, a proapoptotic $\mathrm{BH} 3$-only protein, regulating the cell proliferation and apoptosis proteins (Gramantieri et al., 2009).

HCC cells showed highly deregulated miR-223 expression and a strong inverse relationship with its downstream target Stathmin 1 (Wong et al., 2008). Murakami et al. (2006) and Li et al. (2008), found that miR-125b that suppress the cell growth and phosphorylation of Akt to be a prognostic marker of HCC. miR-122 found up to $70 \%$ of total miRNA in the liver, modulates cyclin G1, thus influences 533 protein stability and transcriptional activity and reduces invasion capability of HCC-derived cell lines (Fornari et al., 2009). Bcl-w is a direct target of miR-122 that functions as an endogenous apoptosis regulator in these HCC-derived cell lines (Lin et al., 2008). miR-122 is under the transcriptional control of HNF1A, HNF3A and HNF3B and loss of miR-122 results in an increase of cell migration and invasion. From a clinical point of view, miR-122 can be used as a diagnostic and prognostic marker for HCC progression (Coulouarn et al., 2009).

In HCC cell line, miR-34a directly targeted c-Met and reduced both mRNA and protein levels of c-Met, thus blocking cell migration (Li et al., 2009a). miR-18a high expression in HCC tumors (Liu et al., 2009). miR-101 has a downstream target of $\mathrm{v}$-fos oncogene and it is involved in cell invasion and migration in overexpressed HCC cell lines (Li et al., 2009b). Xu et al. (2009) show that miR-195 may block the G(1)/S transition by repressing $\mathrm{Rb}$-E2F signaling through targeting multiple molecules, including cyclin D1, CDK6, and E2F3. Upregulation of miR-143 expression transcribed by NF-kappa B in HBV-HCC promotes cancer cell invasion/migration and tumor metastasis by repression of 
Table 1 | microRNA deregulated in HCC.

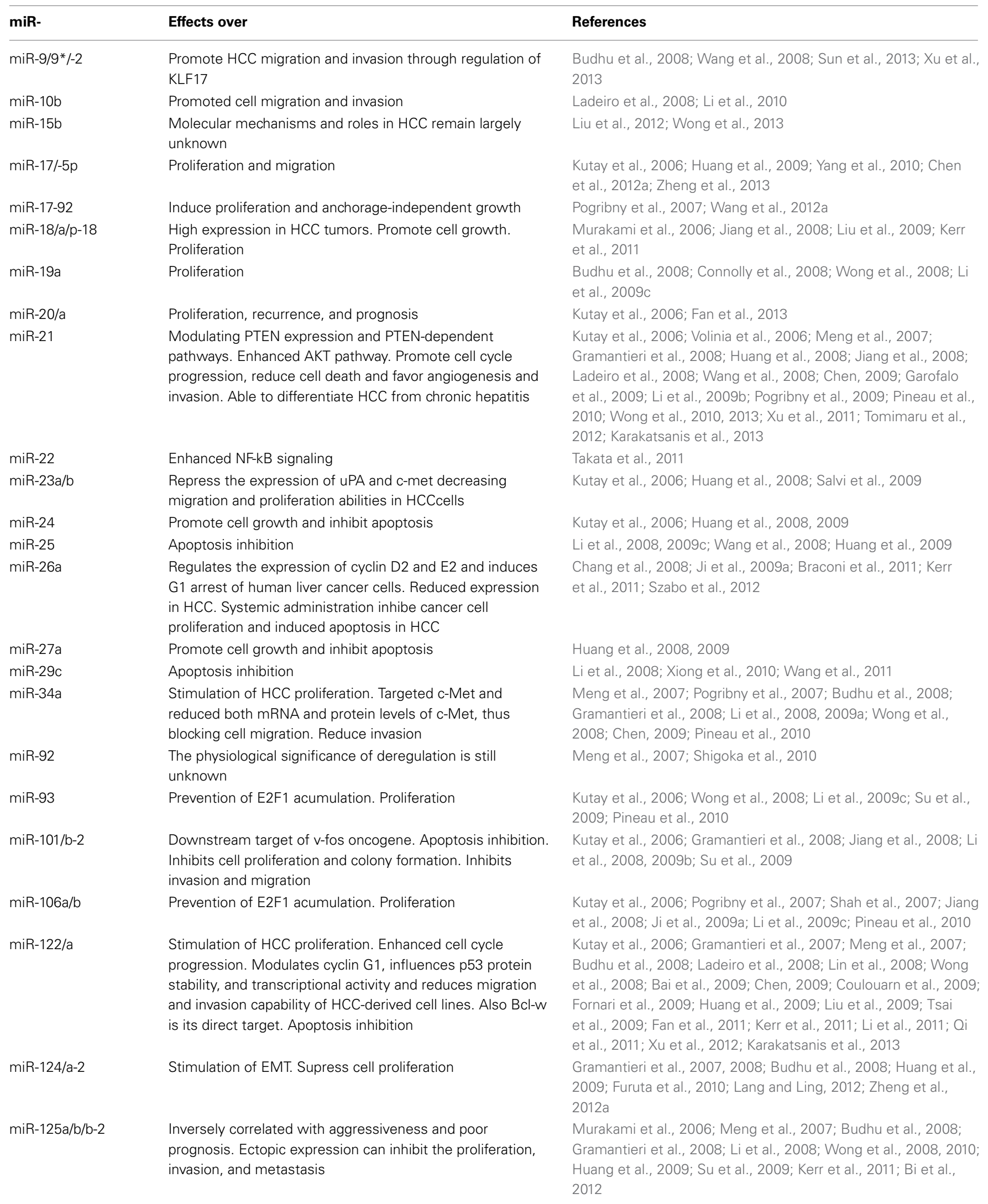


Table 1 | Continued

\begin{tabular}{|c|c|}
\hline miR- & Effects over \\
\hline $\operatorname{miR}-130 / a / a-1 / b$ & $\begin{array}{l}\text { It is still unknown if contribute to HCC development and } \\
\text { tumor progression }\end{array}$ \\
\hline miR-143 & $\begin{array}{l}\text { Promotes cancer cell invasion/migration and tumor } \\
\text { metastasis by repression of fibronectin type III domain } \\
\text { containing 3B (FNDC3B) expression }\end{array}$ \\
\hline miR-145 & Invasion and development \\
\hline miR-146 & Promote cell growth \\
\hline miR-148a/b & Metastasis \\
\hline $\operatorname{miR}-150$ & Cell differentiation and survival \\
\hline miR-151 & Migration and invasion \\
\hline miR-155 & Development and invasion \\
\hline $\begin{array}{l}\operatorname{miR}-181 a / a-1 / a- \\
\text { 2/b/c/d }\end{array}$ & Migration. Enhanced MMP2 and MMP9 \\
\hline miR-182 & Metastasis \\
\hline miR-183 & Onset and progression, Apoptosis \\
\hline miR-185 & Metastasis \\
\hline miR-192 & Inhibition of DNA excision repair \\
\hline miR-194 & Metastasis \\
\hline miR-195 & $\begin{array}{l}\text { Proliferation, colony formation. Repressing Rb-E2F } \\
\text { signaling. Enhanced G1-S transition }\end{array}$ \\
\hline $\begin{array}{l}\operatorname{miR}-199 a / a * / a-1 / a- \\
\text { 2/b/-3p/-5p }\end{array}$ & $\begin{array}{l}\text { MET, the tyrosine kinase HGF receptor, is } \\
\text { post-transcriptionally regulated }\end{array}$ \\
\hline $\mathrm{miR}-200 \mathrm{a} / \mathrm{b} / \mathrm{c}$ & Stimulation of EMT \\
\hline miR-203 & Progression \\
\hline miR-205 & Proliferation \\
\hline miR-207 & Metastasis \\
\hline $\operatorname{miR}-210$ & Metastasis \\
\hline miR-214 & Cell growth and invasion \\
\hline miR-221 & $\begin{array}{l}\text { Proliferation, colony formation, apoptosis, migration. } \\
\text { Down-regulation of p27 and p57. Involved in the modulation } \\
\text { of CDKN1B/p27 and CDKN1 C/p57, cell cycle proteina, and } \\
\text { Bmf, a proapoptotic BH3-only protein. Promote cell cycle } \\
\text { progression, reduce cell death and favor angiogenesis and } \\
\text { invasion. TSC1/2 complex inhibition and enhanced AKT } \\
\text { pathway. Enhanced MMP2 and MMP9. Inhibition of } \\
\text { caspases 3, 6, 7, and } 8\end{array}$ \\
\hline miR-222 & $\begin{array}{l}\text { Enhanced AKT pathway. Enhanced MMP2 and MMP9. } \\
\text { Inhibition of caspases 3, 6, 7, and } 8 \text {. Migration, invasion }\end{array}$ \\
\hline
\end{tabular}

References

Kutay et al., 2006; Gramantieri et al., 2007; Jiang et al., 2008; Wong et al., 2008; Liu et al., 2009, 2012

Gramantieri et al., 2007, 2008; Huang et al., 2009; Zhang et al., 2009

Gramantieri et al., 2007, 2008; Varnholt et al., 2008; Wang et al., 2008; Wong et al., 2008, 2010; Huang et al., 2009; Liu et al., 2009; Borel et al., 2012b; Karakatsanis et al., 2013

Gramantieri et al., 2007; Xu et al., 2008; Karakatsanis et al., 2013 Budhu et al., 2008; Li et al., 2008, 2009b; Wong et al., 2008 Gramantieri et al., 2007, 2009; Jiang et al., 2008; Fornari et al., 2009; Zhang et al., 2009, 2012; Pineau et al., 2010

Wang et al., 2008; Wong et al., 2008; Ding et al., 2010 Gramantieri et al., 2007; Wang et al., 2008; Huang et al., 2012 Gramantieri et al., 2007; Meng et al., 2007; Li et al., 2008; Garofalo et al., 2009; Ji et al., 2009a; Pogribny et al., 2009; Wang et al., 2010; Song et al., 2013

Wang et al., 2008, 2012b; Wong et al., 2008, 2010

Wang et al., 2008; Wong et al., 2008, 2010; Liang et al., 2013 Budhu et al., 2008; Wong et al., 2008, 2010; Huang et al., 2009; Zhi et al., 2013

Xie et al., 2011

Budhu et al., 2008; Huang et al., 2009; Meng et al., 2010; Xu et al., 2013

Murakami et al., 2006; Gramantieri et al., 2007, 2008; Wong et al., 2008, 2010; Huang et al., 2009; Liu et al., 2009; Xu et al., 2009

Murakami et al., 2006; Gramantieri et al., 2007, 2008; Meng et al., 2007; Jiang et al., 2008; Wong et al., 2008, 2010; Chen, 2009; Liu et al., 2009; Su et al., 2009; Wang et al., 2009a; Kerr et al., 2011; Borel et al., 2012b

Murakami et al., 2006; Gramantieri et al., 2007; Jiang et al., 2008; Huang et al., 2009; Wong et al., 2010; Kim et al., 2011; Zhou et al., 2012; Karakatsanis et al., 2013

Ladeiro et al., 2008; Chen et al., 2012b

Huang et al., 2009; Wei et al., 2013a

Budhu et al., 2008; Huang et al., 2009

Meng et al., 2007; Wong et al., 2008; Su et al., 2009; Pineau et al., 2010; Ying et al., 2011

Gramantieri et al., 2007; Jiang et al., 2008; Li et al., 2008; Wang et al., 2008; Wong et al., 2008, 2010

Volinia et al., 2006; Gramantieri et al., 2007, 2008, 2009; Meng et al., 2007; Fornari et al., 2008; Jiang et al., 2008; Li et al., 2008, 2011; Wang et al., 2008; Wong et al., 2008; Chen, 2009; Garofalo et al., 2009; Huang et al., 2009; Liu et al., 2009; Pogribny et al., 2009; Pineau et al., 2010; Wang et al., 2010; Kerr et al., 2011; Karakatsanis et al., 2013

Gramantieri et al., 2007; Meng et al., 2007; Ladeiro et al., 2008; Li et al., 2008; Wang et al., 2008, 2010; Wong et al., 2008, 2010; Garofalo et al., 2009; Huang et al., 2009; Liu et al., 2009; Pogribny et al., 2009; Su et al., 2009; Pineau et al., 2010; Karakatsanis et al., 2013

Gramantieri et al., 2007, 2008; Jiang et al., 2008; Wong et al., 2008; Liu et al., 2009; Xu et al., 2011; Karakatsanis et al., 2013 
Table 1 | Continued

\begin{tabular}{|c|c|c|}
\hline miR- & Effects over & References \\
\hline $\operatorname{miR}-224$ & $\begin{array}{l}\text { Promotes proliferation and inhibits apoptosis inhibitor-5 } \\
\text { (API-5) transcript expression }\end{array}$ & $\begin{array}{l}\text { Murakami et al., 2006; Meng et al., 2007; Gramantieri et al., } \\
\text { 2008; Ladeiro et al., 2008; Li et al., 2008; Wang et al., 2008; } \\
\text { Chen, 2009; Huang et al., 2009; Liu et al., 2009; Su et al., 2009; } \\
\text { Pineau et al., 2010; Wong et al., } 2010\end{array}$ \\
\hline $\operatorname{miR}-296-5 p$ & $\begin{array}{l}\text { It is still unknown if contribute to HCC development and } \\
\text { tumor progression }\end{array}$ & $\begin{array}{l}\text { Borel et al., 2012b; Katayama et al., 2012; Vaira et al., 2012; Wei } \\
\text { et al., 2013b }\end{array}$ \\
\hline miR-338/-3p & $\begin{array}{l}\text { Associated with clinical HCC aggressiveness. Stimulation of } \\
\text { HCC proliferation }\end{array}$ & $\begin{array}{l}\text { Budhu et al., 2008; Gramantieri et al., 2008; Huang et al., 2009, } \\
2011\end{array}$ \\
\hline $\operatorname{miR}-373$ & Invasion and metastasis & Meng et al., 2007; Bartels and Tsongalis, 2009; Wu et al., 2011 \\
\hline miR-374 & Development & Wang et al., 2008; Wong et al., 2008, 2010; Koh et al., 2013 \\
\hline miR-375 & Stimulation of HCC proliferation & Liu et al., 2010; He et al., 2012 \\
\hline miR-376a & Proliferation and apoptosis & Meng et al., 2007; Zheng et al., 2012b \\
\hline miR-423 & Enhanced CDK2 activity & Lin et al., 2011 \\
\hline $\operatorname{miR}-491-5 p$ & Inhibition of TNF- $\alpha$-related apoptosis & Yoon et al., 2010 \\
\hline $\operatorname{miR}-500$ & $\begin{array}{l}\text { Elevated in HCC, returned to physiologic level after surgical } \\
\text { intervention }\end{array}$ & Yamamoto et al., 2009 \\
\hline miR-637 & Active STAT3 & Zhang et al., 2011 \\
\hline $\begin{array}{l}\text { let-7a/a-1/a- } \\
\text { 2/b/c/d/e/f/f-2/g }\end{array}$ & $\begin{array}{l}\text { Development. Enhanced HCC proliferation, colony } \\
\text { formation, and cell migration }\end{array}$ & $\begin{array}{l}\text { Gramantieri et al., 2007, 2008; Budhu et al., 2008; Li et al., } \\
\text { 2008; Wong et al., 2008; Huang et al., 2009; Liu et al., 2009; Ji } \\
\text { et al., 2010; Pineau et al., 2010; Kerr et al., 2011; Lan et al., 2011; } \\
\text { Sukata et al., 2011; Zhou et al., } 2012\end{array}$ \\
\hline
\end{tabular}

Potential biomarkers of aflatoxin exposure.

fibronectin type III domain containing 3B (FNDC3B) expression (Zhang et al., 2009).

The level of miR-338 expression can be associated with clinical aggressiveness of HCC (Huang et al., 2009). miR-23b can recognize target sites in the 3-UTR of uPA and of c-met mRNAs and translationally repress the expression of uPA and c-met decreasing migration and proliferation abilities in HCC cells (Salvi et al., 2009).

MiR-126 down-regulation has been suggested to be directly linked to alcohol-induced hepatocarcinogenesis (Morgan et al., 2004). Microarray profiling studies showed reduction in miRNAs expression specific of HCV and HBV-associated cases: downregulation of miR-190, miR-134, and miR-151 occurs in HCV cases, and of miR-23a, miR-142-5p, miR-34c, in HBV cases (Ura et al., 2009). MiR-96 was reported to be distinctively upregulated in HBV-associated HCC (Ladeiro et al., 2008), whereas miR-193b upregulation has been found upon transfection of HCV genome (Braconi et al., 2010). As quoted above, up-regulation of miRNAs, including miR-17-92 cluster, miR-106a, and miR-34, occurs during tamoxifen-induced hepatocarcinogenesis in female rats (Pogribny et al., 2007), also long-term-administration of 2-AAF resulted in disruption of regulatory miR-34a-p53 feed-back loop (Pogribny et al., 2009). In mice administered a choline-deficient and amino acid-defined diet, in which steatohepatitis precedes HCC development, microarray analysis identified that miR-155 was consistently up-regulated (Wang et al., 2009b).

Ross et al. (2010) analyzed the miRNA expression levels in control and conazole-treated mice. Conazol exposure induced many more changes in miRNA expression. All but one of the altered miRNAs were downregulated compared to controls. The authors suggest that this pattern of the altered miRNA expression represents a signature for tumorigenic conazole exposure in mouse liver.

This newly emerging area of research should unravel novel biomarkers of diagnostic as well as prognostic value in HCC.

\section{microRNA AND AFLATOXIN B1}

Exposure to environmental carcinogens may affect miRNAs expression in liver cells. While this concept is largely acceptable in principle, the specific miRNAs that are deregulated by various toxic and/or carcinogenic agents are yet to be fully documented. What we know at best today is the end-point of the process: the miRNAs whose expression is altered in HCCs (Table 1). However, results from some reports suggest that changes in expression of miRNAs may occur early in the process (Jiang et al., 2008), and these changes may be related to specific etiological factors, such as AFB1. These still preliminary evidences suggest the possibility of using miRNAs as early markers for aflatoxins exposure.

Exposure to natural or chemical environmental agents contributes to HCC development (Wild, 2009). In this context, uncovering relationships between exposure to environmental carcinogens and expression of miRNAs may reveal practical and sensitive biomarkers of toxic exposures and/or carcinogenicity testing (Wang et al., 2009a). A few reports addressed this hypothesis and revealed the existence of differential miRNAs expression patterns in HCCs in accordance with specific risk factors suggesting that exposure to specific risk factors could be responsible for the appearance of characteristic pathogenetic miRNA signatures (Elamin et al., 2011).

Although the precise roles of miRNA in the response to xenobiotics, drugs and chemical toxicants, remain to be established, there is little doubt that miRNAs are important in the cellular 
and in vivo responses to xenobiotics (Taylor and Gant, 2008). At this time, no specific studies on the effect of AFB1 on miRNA expression have been reported.

The field of miRNA and toxicology, particularly as it pertains to AFB1 toxicological outcome, is still in its beginnings. Nonetheless, there seems to be an increasing interest among toxicologists trying to understand the contribution of miRNA in regulating various toxicological outcomes through regulation of gene expression. A number of questions need to be addressed, such as a global role of miRNAs in cellular toxicity and disease; how miRNA biogenesis and expression affect susceptibility/resistance to xenobiotic-induced toxicity or disease (Taylor and Gant, 2008); whether cellular miRNAs form a regulatory networks and how perturbations of such network can cause toxicity/disease including developmental toxicity; how miRNAs may regulate transgenerational toxicological response through epigenetic regulation of gene and genome expression; as well as whether homologous miRNAs can be identified in an animal species based on known miRNA species and their action in other species or even in plant kingdom (Choudhuri, 2010).

Until today specific microRNAs as markers for aflatoxinexposure and their reliability are currently lacking. The following are some potential candidates based on their elucidated mechanisms of action.

The high expression of miR-122 in the liver appears to correlate with a central role in various functions of normal and diseased livers (Lewis and Jopling, 2010; Negrini et al., 2011). It provides a very attractive target for aflatoxins. Rather surprisingly, given the high intracellular levels and numerous targets of miR-122, inactivation of the miRNA does not have any apparent adverse effects on liver physiology. However, reduced miR-122 expression does show an association with hepatocellular carcinoma, and further work will be necessary. In HCC, miR-122 is downregulated in approximately $70 \%$ of cases, suggesting a tumor suppressor function for this miRNA (Bai et al., 2009; Fornari et al., 2009; Ma et al., 2010; Callegari et al., 2013). In addition, loss of miR-122 expression in patients with liver cancer is correlated with the presence of metastasis and a shorter time to recurrence (Coulouarn et al., 2009; Fornari et al., 2009; Tsai et al., 2009). The role of miR-122 in liver cancer has been demonstrated directly by the generation of miR-122 knockout mice (Hsu et al., 2012; Tsai et al., 2012) These mice were characterized by hepatic inflammation, fibrosis, and development of spontaneous tumors similar to HCC, demonstrating the tumor-suppressor function of this miRNA and its important role in liver metabolism and differentiation of hepatocytes (Jensen et al., 2003; Gramantieri et al., 2007; Lin et al., 2008; Bai et al., 2009; Fornari et al., 2009; Tsai et al., 2009; Callegari et al., 2013).

On the other hand, up-regulation of miR-221, may be involved from the very early stage of hepatocarcinogenesis, and expression of the miRNA may progressively increase during malignant transformation. Especially, high expression of miR-221 can be used to predict local recurrence of HCC, and fold changes in miR-221 less than 1 can be used as a predictive marker of metastasis after curative surgical resection in patients with HCC (Yoon et al., 2011). Thus, among the miRNAs that are upregulated in HCC, there is evidence in support of the tumor-promoting activity of miR-221.
It is upregulated in $70-80 \%$ of HCC samples (Fornari et al., 2008). From a functional point of view, HCC cells overexpressing miR-221 show increased growth, proliferation, migration, and invasion capability (Fornari et al., 2008; Medina et al., 2008; Garofalo et al., 2009; Gramantieri et al., 2009; Pineau et al., 2010; Callegari et al., 2012). Additionally, high level of miR-221 positively correlated with cirrhosis, tumor size and tumor stage, and negatively correlated with overall survival. miR-221 serum level monitoring could be of clinical relevance as a potential diagnosis tool and biomarker of treatment efficacy. It remains to be established which miRNA can sensitively and reliably be correlated with the presence of HCC at early stages of disease development and prognosis (Borel et al., 2012a).

miR-429 expression increased AFB1-DNA adducts in the SMMC-7721 Cells. To explore the effects of miR-429 expression on AFB1-DNA formation, Huang et al. (2013), accomplished a toxin experiment of AFB1 in the SMMC-7721 cells transfected by different mimics. Results showed that group with overexpression of miR-429 had elevated levels of AFB1-DNA adducts compared with control group. MiR-429 is classified as a member of miR-200 family and may play an important role in tumor prognosis. Overexpression of miR-429 induces cell proliferation and inhibits cell apoptosis. On the contrary, the suppression of miR-429 expression hindered cell proliferation and promoted cell apoptosis. These data suggest that this microRNA plays an important role in liver tumorigenesis, and functionally acts as an oncogene in HCC. Increasing evidence has shown that the levels of AFB1-DNA adducts correlate with HCC risk and prognosis, whereas the formation process of AFB1-DNA adducts can be modified by some factors such as detoxifying enzymes and DNA repair enzymes (Long et al., 2006, 2011; Xia et al., 2013). Is possibly that miR-429 can target some detoxification enzyme genes and/or DNA repair genes and reduce their detoxification capacity or DNA repair capacity and subsequently increase DNA damage and promote AFB1-DNA adducts formation. These results provided new insights into the mechanism of HCC induced by AFB1 (Huang et al., 2013).

The maintenance of genomic integrity through efficient DNA repair is essential for propagation of cellular life (Natarajan and Palitti, 2008). Nucleotide excision repair (NER) is one of the most versatile DNA repair system for elimination of bulky DNA adducts caused by environmental agents (Nouspikel, 2009) as AFB1 and other carcinogens. A possibility is that AFB1 could interfere with cellular NER through the regulation of microRNAs. Several miRNAs involved in DNA repair have been identified (Crosby et al., 2009; Yan et al., 2010; Hu and Gatti, 2011). A recent study showed that miR-192 directly targets a NER-associated protein (Georges et al., 2008). A bioinformatic analysis of miRNAs which potentially played a role in NER, show that miR-192, was the most differentially upregulated miRNA. The expression of ERCC3 3 and ERCC4 were reduced when miR-192 was overexpressed. Also has been observed that the relative repair capacity of damage by HepG2 and HeLa cells was reduced (Xie et al., 2011). Since of AFB1 is an important risk factor of HCC and AFB1-DNA adducts are known to be repaired by NER, dietary AFB1 exposure could impaired NER mediated by miRNAs like miR-192. 
miR-500 is an oncofetal miRNA, which is highly expressed in fetal liver, more than in adult normal liver, and aberrantly expressed in HCC. This miRNA was associated with liver maturation in a mouse model of liver development. Levels tended to be higher in HCC lines and tumor samples when compared with matched normal tissue. Importantly, significant difference in miR-500 expression was found between normal liver and liver cirrhosis samples, suggesting that miR-500 expression was upregulated during cirrhosis development. An increased amount of miR-500 was found in the sera of 3 out of 10 HCC patients, which means that liver cancer-specific miRNA such as miR-500 is circulating in the peripheral blood and can be a novel diagnostic marker. These results show that the miR-500 abundance profile in serum of the HCC patients might reflect physiological and/or pathological conditions. However, although results are promising for miRNA-based HCC screening, further validation is suggested (Yamamoto et al., 2009).

miR-148, another candidate. There are also reports suggesting that drug-metabolizing enzymes such as CYP family genes are targeted by certain miRNAs. The expression of drug- and xenobiotic-metabolizing enzymes and nuclear receptors and their regulation by miRNA could be important factors for the outcomes of toxicity (Yokoi and Nakajima, 2011). Members of the CYP family are the most important enzymes catalyzing the metabolism of xenobiotics including drugs, environmental chemicals, and carcinogens. The different profiles of the expression of P450 isoenzymes determine the amount of reactive intermediates formed and the resulting toxic response. $\mathrm{P} 450$ s are also known to bioactivate many procarcinogens to their ultimate carcinogens as in the case of AFB1. Recently, some P450s and nuclear receptors have been found to be post-transcriptionally regulated by miRNAs. Aflatoxin B1 and G1 are known to be oxidized efficiently to genotoxic metabolite(s) by CYP3A (Shimada et al., 1989; Forrester et al., 1990), epoxidation of AFB1 is catalyzed by CYP1A2 and CYP3A4 in humans (Gallagher et al., 1994; Ueng et al., 1995). The role of miRNA in the regulation of the expression of CYP3A4 has been reported, Takagi et al. (2008), found that miR-148 modulated inducible and/or constitutive levels of CYP3A4 in human liver cancer.

miRNAs are important regulators for CYP3A. Among these differentially regulated miRNAs, miR-155 appears to be the most prominent regulator as it was significantly associated with lower hepatic CYP3A activity (Vuppalanchi et al., 2013). CYP3A4 is the most abundant hepatic and intestinal CYP enzyme in humans, contributing to the metabolism of various drugs (Gonzalez and Yu, 2006), as AFB1. Pan et al. (2009) suggest that intervention of miRNA pathways may modify CYP3A4 expression and alter CYP3A4-catalyzed drug activation. Of particular note, miR148a has been shown to control post-transcriptional regulation of PXR and, consequently, affect the expression of CYP3A4 (Takagi et al., 2008). Another study suggests that miR-27a and miR-27b may target RXR and regulated of CYP3A4 transcriptional expression (Ji et al., 2009b). The results indicate that intervention of miRNA pathways can be translated into an altered sensitivity of cells to xenobiotics. These findings may provide increased understanding of the complex regulation of CYP3A4 expression, as well as determine the role of miRNAs in drug metabolism and disposition (Pan et al., 2009).

Aflatoxin B1 (AFB1) is carcinogenic due its potential in inducing the oxidative stress and distortion of the most antioxidant enzymes (Abdel-Wahhab et al., 2007; El-Agamy, 2010; AlmEldeen et al., 2013). Recently, the role of miRNAs in oxidative stress-mediated etiology is emerging. Dong et al. (2013) found that miR-214 directly bound to $3^{\prime}$-UTR of the GSR and POR genes, and repressed their endogenous expressions and activities. These findings suggested miR-214 mediating down-regulation of glutathione reductase and CYP oxidoreductase genes might play an important role in oxidative stress in live cells. Wang et al. (2008, 2013) reported that miR-214 is one of the most significantly downregulated miRNAs in HCC patients. Extensive research has suggested that continued oxidative stress is a common pathologic pathway for most chronic diseases including cancer, and liver diseases. Therefore, Dong et al. (2013) postulated that miR-214 could be a key post-transcriptional regulator in oxidative stressmediated human diseases. This microRNA will be also an important molecule to study in oxidative stress induced by AFB1 in liver.

Future validation for all of these miRNAs will be needed to assess their prognostic significance. It is notable that only a few miRNA signatures could potentially be used for diagnosis and prognosis, and even for these there is still a long way to go before they can be used in clinics. To achieve this goal, the miRNA signatures need to be further validated with high accuracy in prospective studies (Ji and Wang, 2009).

\section{FUTURE PERSPECTIVES IN TOXICOLOGICAL RESEARCH}

There is a need for novel markers that would combine the less invasiveness of a blood test and serve as a reliable early detection method. miRNAs definitely have this potential because not only they can be detected in plasma, but their sensitivity and stability are suitable for a clinical setting. Depending on the method, as little as one copy can be detected. The discovery of circulating miRNAs offers interesting clinical perspectives but this field of research is quite recent and more work has to be done.

Recently, measurement of circulating miRNAs has shown promise in identification of new biomarkers of liver injury. Further studies are needed to evaluate the sensitivity and specificity as well as validate the omics biomarkers of hepatotoxicityxenobiotic exposure related.

It is difficult to establish the precise cause-effect relationships among environmental chemicals, miRNA alterations, and diseases. Future studies will need to demonstrate the contribution of environment-miRNA interaction to environmental human disease. The rapidly growing evidence linking miRNAs and environmental chemical, coupled with the unique regulatory role of miRNAs in gene expression, makes miRNAs potential biomarkers for elucidating the mechanisms and developing more effective prevention strategies for environmental diseases (Hou et al., 2011).

Currently, over five billion people worldwide experience uncontrolled exposure to aflatoxin (Strosnider et al., 2006). What remains unknown is how many liver cancer cases can be attributed to this aflatoxin exposure worldwide. Recently Liu and $\mathrm{Wu}$ (2010) have developed a risk assessment for the contribution 
of aflatoxin to the global burden of HCC. Of the 550,000600,000 new HCC cases worldwide per year, they estimate about 25,200-155,000 (4.6-28.2\%) may be attributable to aflatoxin exposure alone. The broad range in the estimate reflects limitations in determining levels of aflatoxin exposures, uncertainties in the nature of the dose-response curve, uncertainties in the mode of interaction between aflatoxins and viruses, and incomplete data on the prevalence of $\mathrm{HBV}$ in different regions of the world. Data driven estimates of the noncarcinogenic health effects of aflatoxins in humans have not been undertaken (Kensler et al., 2011).

The understanding of miRNA biology has advanced greatly in recent years, and the continuous technological advances in accurate miRNA detection, prospect a very promising role for miRNAs as novel biomarkers of environmental chemical exposure-related diseases Identifying chemical-specific miRNAs will not only help our understanding of environmental disease, but may open the way to novel biomonitoring and preventive strategies. Therefore, it is critically important to be able to identify and validate miRNAs that can be induced by specific environmental chemicals and regulate gene expression (Hou et al., 2011).

Understanding the miRNAs roles in toxicological processes requires overall a toxicogenomic approach. On the other hand, miRNA profiling data looks promising as a tool to predict the potential toxicity of unknown compounds. Thus, miRNA signatures of a known toxic compound may include miRNAs related to cellular response to stress, xenobiotic metabolism, and/or DNA repair. These signatures derived from supervised classification algorithms may effectively identify potential toxic compounds. Several examples of miRNAs active in cellular stress as well as in interactions of a number of toxicants. miRNA profiling may lead to the discovery of miRNA exposure biomarkers, which might work as sentinel molecules to better predict both efficacy and safety. The miRNA field in toxicology is still in its early stages. However, progress is occurring at a fast pace and the numbers of publications featuring miRNAs are increasing. As the roles of miRNAs in cellular response to xenobiotic stress and the development of physiological changes and other toxicological phenomenon such susceptibility and resistance are gradually uncovered, the coming years promise to be full of exciting avenues of miRNA research in toxicogenomics (Lema and Cunningham, 2010).

Potential microRNAs that could serve as possible markers of HCC by exposure to aflatoxins are miR-27a, miR-27b, miR-122, miR-148, miR-155, miR-192, miR-214, miR-221, miR-429, and miR-500. Future studies should include some of these microRNAs and confirm their relationship with the induction of HCC due to aflatoxin exposure.

\section{REFERENCES}

Abdel-Wahhab, M. A., Omara, E. A., Abdel-Galil, M. M., Hassan, N. S., Nada, S. A., Saeed, A., et al. (2007). Zizyphus spina-christi extract protects against aflatoxin B1-initiated hepatic carcinogenicity. Afr. J. Tradit. Complement. Altern. Med. 4, 248-256.

Alm-Eldeen, A. A., Mona, M. H., Shati, A. A., and El-Mekkawy, H. I. (2013). Synergistic effect of black tea and curcumin in improving the hepatotoxicity induced by aflatoxin B1 in rats. Toxicol. Ind. Health. doi: 10.1177/0748233713 491807. [Epub ahead of print].
Arenas-Huertero, F., Apátiga-Vega, E., Miguel-Pérez, G., Villeda-Cuevas, D., and Trillo-Tinoco, J. (2011). "Molecular markers associated with the biological response to aromatic hydrocarbons from urban air in humans," in Air Pollution: New Developments, Chapter 4. ed A. M. Moldoveanu (Croacia: INTECH), 87-112.

Avissar-Whiting, M., Veiga, K. R., Uhl, K. M., Maccani, M. A., Gagne, L. A., Moen, E. L., et al. (2010). Bisphenol A exposure leads to specific microRNA alterations in placental cells. Reprod. Toxicol. 29, 401-406. doi: 10.1016/j.reprotox.2010.04.004

Bai, S., Nasser, M. W., Wang, B., Hsu, S. H., Datta, J., Kutay, H., et al. (2009). MicroRNA-122 inhibits tumorigenic properties of hepatocellular carcinoma cells and sensitizes these cells to sorafenib. J. Biol. Chem. 284, 32015-32027. doi: 10.1074/jbc.M109.016774

Bartels, C. L., and Tsongalis, G. J. (2009). microRNAs: novel biomarkers for human cancer. Clin. Chem. 55, 623-631. doi: 10.1373/clinchem.2008.112805

Bennett, R. A., Essigmann, J. M., and Wogan, G. N. (1981). Excretion of an aflatoxin-guanine adduct in the urine of aflatoxin B1-treated rats. Cancer Res. $41,650-654$.

Bi, Q., Tang, S., Xia, L., Du, R., Fan, R., Gao, L., et al. (2012). Ectopic expression of MiR-125a inhibits the proliferation and metastasis of hepatocellular carcinoma by targeting MMP11 and VEGF. PLoS ONE 7:e40169. doi: 10.1371/journal.pone.0040169

Bollati, V., Marinelli, B., Apostoli, P., Bonzini, M., Nordio, F., Hoxha, M., et al. (2010). Exposure to metal-rich particulate matter modifies the expression of candidate microRNAs in peripheral blood leukocytes. Environ. Health Perspect. 118, 763-768. doi: 10.1289/ehp.0901300

Borel, F., Han, R., Visser, A., Petry, H., van Deventer, S. J., Jansen, P. L., et al. (2012b). Adenosine triphosphate-binding cassette transporter genes up-regulation in untreated hepatocellular carcinoma is mediated by cellular microRNAs. Hepatology 55, 821-832. doi: 10.1002/hep.24682

Borel, F., Konstantinova, P., and Jansen, P. L. (2012a). Diagnostic and therapeutic potential of miRNA signatures in patients with hepatocellular carcinoma. J. Hepatol. 56, 1371-1383. doi: 10.1016/j.jhep.2011.11.026

Braconi, C., Henry, J. C., Kogure, T., Schmittgen, T., and Patel, T. (2011). The role of microRNAs in human liver cancers. Semin. Oncol. 38, 752-763. doi: 10.1053/j.seminoncol.2011.08.001

Braconi, C., Valeri, N., Gasparini, P., Huang, N., Taccioli, C., Nuovo, G., et al. (2010). Hepatitis C virus proteins modulate microRNA expression and chemosensitivity in malignant hepatocytes. Clin. Cancer Res. 16, 957-966. doi: 10.1158/1078-0432.CCR-09-2123

Budhu, A., Jia, H. L., Forgues, M., Liu, C. G., Goldstein, D., Lam, A., et al. (2008). Identification of metastasis related microRNAs in hepatocellular carcinoma. Hepatology 47, 897-907. doi: 10.1002/hep.22160

Callegari, E., Elamin, B. K., Giannone, F., Milazzo, M., Altavilla, G., Fornari, F., et al. (2012). Liver tumorigenicity promoted by microRNA-221 in a mouse transgenic model. Hepatology 56, 1025-1033. doi: 10.1002/hep.25747

Callegari, E., Elamin, B. K., Sabbioni, S., Gramantieri, L., and Negrini, M. (2013). Role of microRNAs in hepatocellular carcinoma: a clinical perspective. Onco Targets Ther. 6, 1167-1178. doi: 10.2147/OTT.S36161

Chang, T. C., Yu, D., Lee, Y. S., Wentzel, E. A., Arking, D. E., West, K. M., et al. (2008). Widespread microRNA repression by Myc contributes to tumorigenesis. Nat. Genet. 40, 43-50. doi: 10.1038/ng.2007.30

Chen, H. Y., Han, Z. B., Fan, J. W., Xia, J., Wu, J. Y., Qiu, G. Q., et al. (2012b). miR203 expression predicts outcome after liver transplantation for hepatocellular carcinoma in cirrhotic liver. Med. Oncol. 29, 1859-1865. doi: 10.1007/s12032011-0031-9

Chen, L., Jiang, M., Yuan, W., and Tang, H. (2012a). miR-17-5p as a novel prognostic marker for hepatocellular carcinoma. J. Invest. Surg. 25, 156-161. doi: 10.3109/08941939. 2011.618523

Chen, X.-M. (2009). MicroRNA signatures in liver diseases. World J. Gastroenterol. 15, 1665-1672. doi: 10.3748/wjg.15.1665

Cheng, Y., Liu, X., Zhang, S., Lin, Y., Yang, J., and Zhang, C. (2009). MicroRNA-21 protects against the $\mathrm{H}(2) \mathrm{O}(2)$-induced injury on cardiac myocytes via its target gene PDCD4. J. Mol. Cell. Cardiol. 47, 5-14. doi: 10.1016/j.yjmcc.2009.01.008

Choudhuri, S. (2010). Small noncoding RNAs: biogenesis, function, and emerging significance in toxicology. J. Biochem. Mol. Toxicol. 24, 195-216. doi: $10.1002 /$ jbt. 20325

Connolly, E., Melegari, M., Landgraf, P., Tchaikovskaya, T., Tennant, B. C., Slagle, B. L., et al. (2008). Elevated expression of the miR-17-92 polycistron and 
miR-21 in hepadnavirus-associated hepatocellular carcinoma contributes to the malignant phenotype. Am. J. Pathol. 173, 856-864. doi: 10.2353/ajpath.2008. 080096

Coulouarn, C., Factor, V. M., Andersen, J. B., Durkin, M. E., and Thorgeirsson, S. S. (2009). Loss of miR-122 expression in liver cancer correlates with suppression of the hepatic phenotype and gain of metastatic properties. Oncogene 28, 3526-3536. doi: 10.1038/onc. 2009.211

Crinnion, W. J. (2010). The CDC fourth national report on human exposure to environmental chemicals: what it tells us about our toxic burden and how it assist environmental medicine physicians. Altern. Med. Rev. 15, 101-109.

Crosby, M. E., Kulshreshtha, R., Ivan, M., and Glazer, P. M. (2009). MicroRNA regulation of DNA repair gene expression in hypoxic stress. Cancer Res. 69, 1221-1229. doi: 10.1158/0008-5472.CAN-08-2516

Ding, J., Huang, S., Wu, S., Zhao, Y., Liang, L., Yan, M., et al. (2010). Gain of miR-151 on chromosome 8q24.3 facilitates tumour cell migration and spreading through downregulating RhoGDIA. Nat. Cell Biol. 12, 390-399. doi: $10.1038 /$ ncb2039

Dong, X., Liu, H., Chen, F., Li, D., and Zhao, Y. (2013). MiR-214 promotes the alcohol-induced oxidative stress via down-regulation of glutathione reductase and cytochrome P450 oxidoreductase in liver cells. Alcohol. Clin. Exp. Res. 38, 68-77. doi: 10.1111/acer.12209

Elamin, B. K., Callegari, E., Gramantieri, L., Sabbioni, S., and Negrini, M. (2011). MicroRNA response to environmental mutagens in liver. Mutat. Res. 717, 67-76. doi: 10.1016/j.mrfmmm.2011.03. 015

El-Agamy, D. S. (2010). Comparative effects of curcumin and resveratrol on aflatoxin B1-induced liver injury in rats. Arch. Toxicol. 84, 389-396. doi: 10.1007/s00204-010-0511-2

Elyakim, E., Sitbon, E., Faerman, A., Tabak, S., Montia, E., Belanis, L., et al. (2010). hsa-miR-191 is a candidate oncogene target for hepatocellular carcinoma therapy. Cancer Res. 70, 8077-8087. doi: 10.1158/0008-5472.CAN-10-1313

Etheridge, A., Lee, I., Hood, L., Galas, D., and Wang, K. (2011). Extracellular microRNA: a new source of biomarkers. Mutat. Res. 717, 85-90. doi: 10.1016/j.mrfmmm.2011.03.004

Fan, C. G., Wang, C. M., Tian, C., Wang, Y., Li, L., Sun, W. S., et al. (2011). miR122 inhibits viral replication and cell proliferation in hepatitis B virus-related hepatocellular carcinoma and targets NDRG3. Oncol. Rep. 26, 1281-1286. doi: 10.3892/or.2011.1375

Fan, M. Q., Huang, C. B., Gu, Y., Xiao, Y., Sheng, J. X., and Zhong, L. (2013). Decrease expression of microRNA-20a promotes cancer cell proliferation and predicts poor survival of hepatocellular carcinoma. J. Exp. Clin. Cancer Res. 32, 21. doi: 10.1186/1756-9966-32-21

Fornari, F., Gramantieri, L., Ferracin, M., Veronese, A., Sabbioni, S., Calin, G. A., et al. (2008). MiR-221 controls CDKN1C/p57 and CDKN1B/p27 expression in human hepatocellular carcinoma. Oncogene 27, 5651-5661. doi: 10.1038/onc. 2008.178

Fornari, F., Gramantieri, L., Giovannini, C., Veronese, A., Ferracin, M., Sabbioni, S., et al. (2009). MiR-122/cyclin G1 interaction modulates p53 activity and affects doxorubicin sensitivity of human hepatocarcinoma cells. Cancer Res. 69, 5761-5767. doi: 10.1158/0008-5472.CAN-08-4797

Forrester, L. M., Neal, G. E., Judah, D. J., Glancey, M. J., and Wolf. C. R. (1990). Evidence for involvement of multiple forms of cytochrome P-450 in aflatoxin B1 metabolism in human liver. Proc. Natl. Acad. Sci. U.S.A. 87, 8306-8310. doi: 10.1073/pnas.87.21.8306

Fukushima, T., Hamada, Y., Yamada, H., and Horii, I. (2007). Changes of microRNA expression in rat liver treated by acetaminophen or carbon tetrachlorideregulating role of micro-RNA for RNA expression. J. Toxicol. Sci. 32, 401-409. doi: $10.2131 /$ jts.32.401

Furuta, M., Kozaki, K. I., Tanaka, S., Arii, S., Imoto, I., and Inazawa, J. (2010). MiR-124 and miR-203 are epigenetically silenced tumor-suppressive microRNAs in hepatocellular carcinoma. Carcinogenesis 31, 766-776. doi: $10.1093 /$ carcin/bgp250

Gallagher, E. P., Wienkers, L. C., Stapleton, P. L., Kunze, K. L., and Eaton, D. L. (1994). Role of human microsomal and human complementary DNA-expressed cytochromes P4501A2 and P4503A4 in the bioactivation of aflatoxin B1. Cancer Res. 54, 101-108.

Garofalo, M., Di Leva, G., Romano, G., Nuovo, G., Suh, S. S., Ngankeu, A., et al. (2009). miR-221\&222 regulate TRAIL resistance and enhance tumorigenicity through PTEN and TIMP3 downregulation. Cancer Cell 16, 498-509. doi: 10.1016/j.ccr.2009.10.014
Gatzidou, E. T., Zira, A. N., and Theocharis, S. E. (2007). Toxicogenomics: a pivotal piece in the puzzle of toxicological research. J. Appl. Toxicol. 27, 302-309. doi: 10.1002/jat. 1248

Georges, S. A., Biery, M. C., Kim, S. Y., Schelter, J. M., Guo, J., Chang, A. N., et al. (2008). Coordinated regulation of cell cycle transcripts by p53Inducible microRNAs, miR-192 and miR-215. Cancer Res. 68, 10105-10112. doi: 10.1158/0008-5472.CAN-08-1846

Gonzalez, F. J., and Yu, A. M. (2006). Cytochrome P450 and xenobiotic receptor humanized mice. Annu. Rev. Pharmacol. Toxicol. 46, 41-64. doi: 10.1146/annurev.pharmtox.45. 120403.100007

Gramantieri, L., Ferracin, M., Fornari, F., Veronese, A., Sabbioni, S., Liu, C. G., et al. (2007). Cyclin G1 is a target of miR-122a, a microRNA frequently downregulated in human hepatocellular carcinoma. Cancer Res. 67, 6092-6099. doi: 10.1158/0008-5472.CAN-06-4607

Gramantieri, L., Fornari, F., Callegari, E., Sabbioni, S., Lanza, G., Croce, C. M., et al. (2008). MicroRNA involvement in hepatocellular carcinoma. J. Cell. Mol. Med. 12, 2189-2204. doi: 10.1111/j.1582-4934.2008.00533.x

Gramantieri, L., Fornari, F., Ferracin, M., Veronese, A., Sabbioni, S., Calin, G. A., et al. (2009). MicroRNA-221 targets Bmf in hepatocellular carcinoma and correlates with tumor multifocality. Clin. Cancer Res. 15, 5073-5081. doi: 10.1158/1078-0432.CCR-09-0092

Groopman, J. D., Johnson, D., and Kensler, T. W. (2005). Aflatoxin and hepatitis B virus biomarkers: a paradigm for complex environmental exposures and cancer risk. Cancer Biomark. 1, 5-14.

He, X. X., Chang, Y., Meng, F. Y., Wang, M. Y., Xie, Q. H., Tang, F., et al. (2012). MicroRNA-375 targets AEG-1 in hepatocellular carcinoma and suppresses liver cancer cell growth in vitro and in vivo. Oncogene 31, 3357-3369. doi: 10.1038/onc.2011.500

Hou, L., Wang, D., and Baccarelli, A. (2011). Environmental chemicals and microRNAs. Mutat. Res. 714, 105-112. doi: 10.1016/j.mrfmmm.2011.05.004

Hou, L., Zhang, X., Wang, D., and Baccarelli, A. (2012). Environmental chemicals exposure and human epigenetics. Int. J. Epidemiol. 41, 79-105. doi: 10.1093/ije/dyr154

Hsu, P. Y., Deatherage, D. E., Rodriguez, B. A., Liyanarachchi, S., Weng, Y. I., Zuo, T., et al. (2009). Xenoestrogen-induced epigenetic repression of microRNA9-3 in breast epithelial cells. Cancer Res. 69, 5936-5945. doi: 10.1158/00085472.CAN-08-4914

Hsu, S. H., Wang, B., Kota, J., Yu, J., Costinean, S., Kutay, H., et al. (2012). Essential metabolic, anti-inflammatory, and anti-tumorigenic functions of miR-122 in liver. J. Clin. Invest. 122, 2871-2883. doi: 10.1172/JCI63539

$\mathrm{Hu}, \mathrm{H}$., and Gatti, R. A. (2011). MicroRNAs: new players in the DNA damage response. J. Mol. Cell. Biol. 3, 151-158. doi: 10.1093/jmcb/mjq042

Huang, S., He, X., Ding, J., Liang, L., Zhao, Y., Zhang, Z., et al. (2008). Upregulation of miR-23a approximately 27 a approximately 24 decreases transforming growth factor-beta-induced tumor-suppressive activities in human hepatocellular carcinoma cells. Int. J. Cancer 123, 972-978. doi: 10.1002/ijc.23580

Huang, X. H., Chen, J. S., Wang, Q., Chen, X. L., Wen, L., Chen, L. Z., et al. (2011). miR-338-3p suppresses invasion of liver cancer cell by targeting smoothened. J. Pathol. 225, 463-472. doi: 10.1002/path.2877

Huang, X. H., Wang, Q., Chen, J. S., Fu, X. H., Chen, X. L., Chen, L. Z., et al. (2009). Bead-based microarray analysis of microRNA expression in hepatocellular carcinoma: miR-338 is downregulated. Hepatol. Res. 39, 786-794. doi: 10.1111/j.1872-034X.2009.00502.x

Huang, X. Y., Yao, J. G., Huang, H. D., Wang, C., Ma, Y., Xia, Q., et al. (2013). microRNA-429 modulates hepatocellular carcinoma prognosis and tumorigenesis. Gastroenterol. Res. Pract. 2013: 804128. doi: 10.1155/2013/804128

Huang, Y. H., Lin, K. H., Chen, H. C., Chang, M. L., Hsu, C. W., Lai, M. W., et al. (2012). Identification of postoperative prognostic microRNA predictors in hepatocellular carcinoma. PLoS ONE 7:e37188. doi: 10.1371/journal.pone.0037188

Ilnytskyy, Y., Zemp, F. J., Koturbash, I., and Kovalchuk, O. (2008). Altered microRNA expression patterns in irradiated hematopoietic tissues suggest a sexspecific protective mechanism. Biochem. Biophys. Res. Commun. 377, 41-45. doi: 10.1016/j.bbrc.2008.09.080

Izzotti, A., Calin, G. A., Arrigo, P., Steele, V. E., Croce, C. M., and De Flora, S. (2009b). Downregulation of microRNA expression in the lungs of rats exposed to cigarette smoke. FASEB J. 23, 806-812. doi: 10.1096/fj.08-121384

Izzotti, A., Calin, G. A., Steele, V. E., Croce, C. M., and De Flora, S. (2009a). Relationships of microRNA expression in mouse lung with age and exposure to cigarette smoke and light. FASEB J. 23, 3243-3250. doi: 10.1096/fj.09-135251 
Jardim, M. J., Fry, R. C., Jaspers, I., Dailey, L., and Diaz-Sanchez, D. (2009). Disruption of microRNA expression in human airway cells by diesel exhaust particles is linked to tumorigenesis-associated pathways. Environ. Health Perspect. 117, 1745-1751. doi: 10.1289/ehp.0900756

Jensen, M. R., Factor, V. M., Fantozzi, A., Helin, K., Huh, C. G., and Thorgeirsson, S. S. (2003). Reduced hepatic tumor incidence in cyclin G1-deficient mice. Hepatology 37, 862-870. doi: 10.1053/jhep.2003.50137

Ji, J., Shi, J., Budhu, A., Yu, Z., Forgues, M., Roessler, S., et al. (2009a). MicroRNA expression, survival, and response to interferon in liver cancer. N. Engl. J. Med. 361, 1437-1447. doi: 10.1056/NEJMoa0901282

Ji, J., and Wang, X. W. (2009). New kids on the block: diagnostic and prognostic microRNAs in hepatocellular carcinoma. Cancer Biol. Ther. 8, 1686-1693. doi: $10.4161 /$ cbt.8.18.8898

Ji, J., Zhang, J., Huang, G., Qian, J., Wang, X., and Mei, S. (2009b). Overexpressed microRNA-27a and $27 \mathrm{~b}$ influence fat accumulation and cell proliferation during rat hepatic stellate cell activation. FEBS Lett. 583, 759-766. doi: 10.1016/j.febslet.2009.01.034

Ji, J., Zhao, L., Budhu, A., Forgues, M., Jia, H. L., Qin, L. X., et al. (2010). Let$7 \mathrm{~g}$ targets collagen type I alpha2 and inhibits cell migration in hepatocellular carcinoma. J. Hepatol. 52, 690-697. doi: 10.1016/j.jhep.2009.12. 025

Jiang, J., Gusev, Y., Aderca, I., Mettler, T. A., Nagorney, D. M., Brackett, D. J., et al. (2008). Association of microRNA expression in hepatocellular carcinomas with hepatitis infection, cirrhosis, and patient survival. Clin. Cancer Res. 14, 419-427. doi: 10.1158/1078-0432.CCR-07-0523

Kalscheuer, S., Zhang, X., Zeng, Y., and Upadhyaya, P. (2008). Differential expression of microRNAs in early-stage neoplastic transformation in the lungs of F344 rats chronically treated with the tobacco carcinogen 4(methylnitrosamino)-1-(3-pyridyl)-1-butanone. Carcinogenesis 29, 2394-2399. doi: $10.1093 /$ carcin/bgn209

Karakatsanis, A., Papaconstantinou, I., Gazouli, M., Lyberopoulou, A., Polymeneas, G., and Voros, D. (2013). Expression of microRNAs, miR-21, miR-31, miR-122, miR-145, miR-146a, miR-200c, miR-221, miR-222, and miR-223 in patients with hepatocellular carcinoma or intrahepatic cholangiocarcinoma and its prognostic significance. Mol. Carcinog. 52, 297-303. doi: 10.1002/mc.21864

Katayama, Y., Maeda, M., Miyaguchi, K., Nemoto, S., Yasen, M., Tanaka, S., et al. (2012). Identification of pathogenesis-related microRNAs in hepatocellular carcinoma by expression profiling. Oncol. Lett. 4, 817-823. doi: 10.3892/ol.2012.810

Kensler, T. W., Roebuck, B. D., Wogan, G. N., and Groopman, J. D (2011). Aflatoxin: a 50-year odyssey of mechanistic and translational toxicology. Toxicol. Sci. 120, S28-S48. doi: 10.1093/toxsci/kfq283

Kerr, T. A., Korenblat, K. M., and Davidson, N. O. (2011). MicroRNAs and liver disease. Transl. Res. 4, 241-252. doi: 10.1016/j.trsl.2011.01.008

Kim, T., Veronese, A., Pichiorri, F., Lee, T. J., Jeon, Y. J., Volinia, S., et al. (2011). p53 regulates epithelial-mesenchymal transition through microRNAs targeting ZEB1 and ZEB2. J. Exp. Med. 208, 875-883. doi: 10.1084/jem.20110235

Koh, Y. S., Kim, J. H., Cai, H., Li, L.-H., Kim, H.-S., Kim, K., et al. (2013). Dysregulated microRNAs in non-cirrhotic hepatocellular carcinoma. Genes Genom. 35, 759-765. doi: 10.1007/s13258-013-0126-0

Kutay, H., Bai, S., Datta, J., Motiwala, T., Pogribny, I., Frankel, W., et al. (2006). Downregulation of miR-122 in the rodent and human hepatocellular carcinomas. J. Cell. Biochem. 99, 671-678. doi: 10.1002/jcb.20982

Ladeiro, Y., Couchy, G., Balabaud, C., Bioulac-Sage, P., Pelletier, L., Rebouissou, S., et al. (2008). MicroRNA profiling in hepatocellular tumors is associated with clinical features and oncogene/tumor suppressor gene mutations. Hepatology 47, 1955-1963. doi: 10.1002/hep.22256

Lan, F. F., Wang, H., Chen, Y. C., Chan, C. Y., Ng, S. S., Li, K., et al. (2011). Hsa-let$7 \mathrm{~g}$ inhibits proliferation of hepatocellular carcinoma cells by downregulation of c-Myc and upregulation of p16(INK4A). Int. J. Cancer 128, 319-331. doi: $10.1002 /$ ijc. 25336

Lang, Q., and Ling, C. (2012). MiR-124 suppresses cell proliferation in hepatocellular carcinoma by targeting PIK3CA. Biochem. Biophys. Res. Commun. 426, 247-252. doi: 10.1016/j.bbrc.2012.08.075

Law, P. T., and Wong, N. (2011). Emerging roles of microRNA in the intracellular signaling networks of hepatocellular carcinoma. J. Gastroenterol. Hepatol. 26, 437-449. doi: 10.1111/j.1440-1746.2010.06512.x

Lema, C., and Cunningham, M. J. (2010). MicroRNAs and their implications in toxicological research. Toxicol. Lett. 198, 100-105. doi: 10.1016/j.toxlet.2010.06.019
Lewis, A. P., and Jopling, C. L. (2010). Regulation and biological function of the liver-specific miR-122. Biochem. Soc. Trans. 38, 1553-1557. doi: 10.1042/BST0381553

Li, N., Fu, H., Tie, Y., Hu, Z., Kong, W., Wu, Y., et al. (2009a). miR$34 \mathrm{a}$ inhibits migration and invasion by down-regulation of c-Met expression in human hepatocellular carcinoma cells. Cancer Lett. 275, 44-53. doi: 10.1016/j.canlet.2008.09.035

Li, R., Qian, N., Tao, K., You, N., Wang, X., and Dou, K. (2010). MicroRNAs involved in neoplastic transformation of liver cancer stem cells. J. Exp. Clin. Cancer Res. 29, 169. doi: 10.1186/1756-9966-29-169

Li, S., Fu, H., Wang, Y., Tie, Y., Xing, R., Zhu, J., et al. (2009b). MicroRNA101 regulates expression of the $\mathrm{v}$-fos FBJ murine osteosarcoma viral oncogene homolog (FOS) oncogene in human hepatocellular carcinoma. Hepatology 49, 1194-1202. doi: 10.1002/hep.22757

Li, W., Xie, L., He, X., Li, J., Tu, K., Wei, L., et al. (2008). Diagnostic and prognostic implications of microRNAs in human hepatocellular carcinoma. Int. J. Cancer 123, 1616-1622. doi: 10.1002/ijc.23693

Li, Y., Tan, W., Neo, T. W., Aung, M. O., Wasser, S., Lim, S. G., et al. (2009c). Role of the miR-106b-25 microRNA cluster in hepatocellular carcinoma. Cancer Sci. 100, 1234-1242. doi: 10.1111/j.1349-7006.2009.01164.x

Li, Y. P., Gottwein, J. M., Scheel, T. K., Jensen, T. B., and Bukh, J. (2011). MicroRNA122 antagonism against hepatitis $\mathrm{C}$ virus genotypes 1-6 and reduced efficacy by host RNA insertion or mutations in the HCV $5^{\prime}$ UTR. Proc. Natl. Acad. Sci. U.S.A. 108, 4991-4996. doi: 10.1073/pnas.1016606108

Liang, Z., Gao, Y., Shi, W., Zhai, D., Li, S., Jing, L., et al. (2013). Expression and significance of microRNA-183 in hepatocellular carcinoma. Sci. World J. 2013:381874. doi: 10.1155/2013/381874

Lin, C. J., Gong, H. Y., Tseng, H. C., Wang, W. L., and Wu, J. L. (2008). miR-122 targets an anti-apoptotic gene, Bcl-w, in human hepatocellular carcinoma cell lines. Biochem. Biophys. Res. Commun. 375, 315-320. doi: 10.1016/j.bbrc.2008.07.154

Lin, J., Huang, S., Wu, S., Ding, J., Zhao, Y., Liang, L., et al. (2011). MicroRNA423 promotes cell growth and regulates $\mathrm{G}(1) / \mathrm{S}$ transition by targeting p21Cip1/Waf1 in hepatocellular carcinoma. Carcinogenesis 32, 1641-1647. doi: 10.1093/carcin/bgr199

Lin, Y., Liu, X., Cheng, Y., Yang, J., Huo, Y., and Zhang, C. (2009). Involvement of MicroRNAs in hydrogen peroxide-mediated gene regulation and cellular injury response in vascular smooth muscle cells. J. Biol. Chem. 284, 7903-7913. doi: 10.1074/jbc. M806920200

Liu, A. M., Poon, R. T., and Luk, J. M. (2010). MicroRNA-375 targets Hippo-signaling effector YAP in liver cancer and inhibits tumor properties. Biochem. Biophys. Res. Commun. 394, 623-627. doi: 10.1016/j.bbrc.2010. 03.036

Liu, A. M., Yao, T. J., Wang, W., Wong, K. F., Lee, N. P., Fan, S. T., et al. (2012). Circulating miR-15b and miR-130b in serum as potential markers for detecting hepatocellular carcinoma: a retrospective cohort study. BMJ Open 2:e000825. doi: 10.1136/bmjopen-2012-000825

Liu, W. H., Yeh, S. H., Lu, C. C., Yu, S. L., Chen, H. Y., Lin, C. Y., et al. (2009). MicroRNA-18a prevents estrogen receptoralpha expression, promoting proliferation of hepatocellular carcinoma cells. Gastroenterology 136, 683-693. doi: 10.1053/ j.gastro.2008.10. 029

Liu, Y., and Wu, F. (2010). Global burden of aflatoxin-induced hepatocellular carcinoma: a risk assessment. Environ. Health Perspect. 118, 818-824. doi: 10.1289/ehp.0901388

Long, X.-D., Ma, Y., Wei, Y. P., and Deng, Z. L. (2006). The polymorphisms of GSTM1, GSTT1, HYL1*2, and XRCC1, and aflatoxin B1-related hepatocellular carcinoma in Guangxi population, China. Hepatol. Res. 36, 48-55. doi: 10.1016/j.hepres.2006.06.004

Long, X.-D., Yao, J.-G., Zeng, Z., Huang, C.-H., Liao, P., Huang, Z.-S., et al. (2011). "DNA Repair capacity-related to genetic polymorphisms of DNA repair genes and aflatoxin B1-related hepatocellular carcinoma among Chinese population, chapter 25," in DNA Repair, ed I. Kruman (Rijeka: InTech), 505-524.

Lu, J., Getz, G., Miska, E. A., Alvarez-Saavedra, E., Lamb, J., Peck, D., et al. (2005). MicroRNA expression profiles classify human cancers. Nature 435, 834-838. doi: $10.1038 /$ nature 03702

Lukiw, W. J., and Pogue, A. I. (2007). Induction of specific micro RNA (miRNA) species by ROS-generating metal sulfates in primary human brain cells. J. Inorg. Biochem. 101, 1265-1269. doi: 10.1016/j.jinorgbio.2007.06.004 
Ma, L., Liu, J., Shen, J., Liu, L., Wu, J., Li, W., et al. (2010). Expression of miR-122 mediated by adenoviral vector induces apoptosis and cell cycle arrest of cancer cells. Cancer Biol. Ther. 9, 554-561. doi: 10.4161/cbt.9.7.11267

Marsit, C. J., Eddy, K., and Kelsey, K. T. (2006). MicroRNA responses to cellular stress. Cancer Res. 66, 10843-10848. doi: 10.1158/0008-5472.CAN-06-1894

Medina, R., Zaidi, S.K., Liu, C.G., Stein, J.L., van Wijnen, A.J., Croce, C.M., et al. (2008). MicroRNAs 221 and 222 bypass quiescence and compromise cell survival. Cancer Res. 68, 2773-2780. doi: 10.1158/0008-5472.CAN07-6754

Meng, F., Henson, R., Wehbe-Janek, H., Ghoshal, K., Jacob, S. T., and Patel, T. (2007). MicroRNA-21 regulates expression of the PTEN tumor suppressor gene in human hepatocellular cancer. Gastroenterology 133, 647-658. doi: 10.1053/j.gastro.2007.05.022

Meng, Z., Fu, X., Chen, X., Zeng, S., Tian, Y., Jove, R., et al. (2010). miR-194 is a marker of hepatic epithelial cells and suppresses metastasis of liver cancer cells in mice. Hepatology 52, 2148-2157. doi: 10.1002/hep. 23915

Moffat, I. D., Boutros, P. C., Celius, T., Linden, J., Pohjanvirta, R., and Okey, A. B. (2007). microRNAs in adult rodent liver are refractory to dioxin treatment. Toxicol. Sci. 99, 470-487. doi: 10.1093/toxsci/kfm189

Mohri, T., Nakajima, M., Takagi, S., Komagata, S., and Yokoi, T. (2009). MicroRNA regulates human vitamin D receptor. Int. J. Cancer 125, 1328-1333. doi: 10.1002/ijc.24459

Morgan, T. R., Mandayam, S., and Jamal, M. M. (2004). Alcohol and hepatocellular carcinoma. Gastroenterology 127, S87-S96. doi: 10.1053/j.gastro.2004.09.020

Murakami, Y., Yasuda, T., Saigo, K., Urashima, T., Toyoda, H., Okanoue, T., et al. (2006). Comprehensive analysis of microRNA expression patterns in hepatocellular carcinoma and nontumorous tissues. Oncogene 25, 2537-2545. doi: 10.1038/sj.onc. 1209283

Natarajan, A. T., and Palitti, F. (2008). DNA repair and chromosomal alterations. Mutat. Res. 657, 3-7. doi: 10.1016/j.mrgentox.2008.08.017

Negrini, M., Gramantieri, L., Sabbioni, S., and Croce, C. M. (2011). microRNA involvement in hepatocellular carcinoma. Anticancer Agents Med. Chem. 11, 500-521. doi: 10.2174/ 187152011796011037

Newbold, R. R. (2010). Impact of environmental endocrine disrupting chemicals on the development of obesity. Hormones (Athens) 9, 206-217. doi: 10.14310/horm.2002.1271

Nouspikel, T. (2009). DNA repair in mammalian cells: nucleotide excision repair: variations on versatility. Cell. Mol. Life Sci. 66, 994-1009. doi: 10.1007/s00018009-8737-y

Pan, Y. Z., Gao, W., and Yu, A. M. (2009). microRNAs regulate CYP3A4 expression via direct and indirect targeting. Drug Metab. Dispos. 37, 2112-2117. doi: 10.1124/dmd.109.027680

Patel, C. J., and Butte, A. J. (2010). Predicting environmental chemical factors associated with disease-related gene expression data. BMC Med. Genom. 3:17. doi: 10.1186/1755-8794-3-17

Pineau, P., Volinia, S., McJunkin, K., Marchio, A., Battiston, C., Terris, B., et al. (2010). miR-221 overexpression contributes to liver tumorigenesis. Proc. Natl. Acad. Sci. U.S.A. 107, 264-269. doi: 10.1073/pnas. 0907904107

Pogribny, I. P., Muskhelishvili, L., Tryndyak, V. P., and Beland, F. A. (2009). The tumor-promoting activity of 2-acetylaminofluorene is associated with disruption of the p53 signaling pathway and the balance between apoptosis and cell proliferation. Toxicol. Appl. Pharmacol. 235, 305-311. doi: 10.1016/j.taap.2008.12.021

Pogribny, I. P., Tryndyak, V. P., Boyko, A., Rodriguez-Juarez, R., Beland, F. A., and Kovalchuk, O. (2007). Induction of microRNAome deregulation in rat liver by long-term tamoxifen exposure. Mutat. Res. 619, 30-37. doi: 10.1016/j.mrfmmm.2006.12.006

Pogue, A. I., Li, Y. Y., Cui, J. G., Zhao, Y., Kruck, T. P., Percy, M. E., et al. (2009). Characterization of an NF-kappaB-regulated, miRNA146a-mediated down-regulation of complement factor $\mathrm{H}(\mathrm{CFH})$ in metalsulfate-stressed human brain cells. J. Inorg. Biochem. 103, 1591-1595. doi: 10.1016/j.jinorgbio.2009.05.012

Qi, P., Cheng, S. Q., Wang, H., Li, N., Chen, Y. F., and Gao, C. F. (2011). Serum microRNAs as biomarkers for hepatocellular carcinoma in Chinese patients with chronic hepatitis B virus infection. PLoS ONE 6:e28486. doi: 10.1371/journal.pone.0028486

Qu, K. Z., Zhang, K., Li, H., Afdhal, N. H., and Albitar, M. (2011). Circulating microRNAs as biomarkers for hepatocellular carcinoma. J. Clin. Gastroenterol. 45, 355-360. doi: 10.1097/MCG.0b013e3181f18ac2
Ross, J. A., Blackman, C. F., Thai, S. F., Li, Z., Kohan, M., Jones, C. P., et al. (2010). A potential microRNA signature for tumorigenic conazoles in mouse liver. Mol. Carcinog. 49, 320-323. doi: 10.1002/mc.20620

Rossi, L., Bonmassar, E., and Faraoni, I. (2007). Modification of miR- gene expression pattern in human colon cancer cells following exposure to 5-fluorouracil in vitro. Pharmacol. Res. 56, 248-253. doi: 10.1016/j.phrs.2007.07.001

Sabbioni, G., Skipper, P. L., Buchi, G., and Tannenbaum, S. R. (1987). Isolation and characterization of the major serum albumin adduct formed by aflatoxin $\mathrm{B} 1$ in vivo in rats. Carcinogenesis 8, 819-824. doi: 10.1093/carcin/8.6.819

Salvi, A., Sabelli, C., Moncini, S., Venturin, M., Arici, B., Riva, P., et al. (2009). MicroRNA-23b mediates urokinase and c-met downmodulation and a decreased migration of human hepatocellular carcinoma cells. FEBS J. 276, 2966-2982. doi: 10.1111/j.1742-4658.2009.07014.x

Sathyan, P., Golden, H. B., and Miranda, R. C. (2007). Competing interactions between micro-RNAs determine neural progenitor survival and proliferation after ethanol exposure: evidence from an ex vivo model of the fetal cerebral cortical neuroepithelium. J. Neurosci. 27, 8546-8557. doi: 10.1523/JNEUROSCI.1269-07.2007

Schembri, F., Sridhar, S., Perdomo, C., Gustafson, A. M., Zhang, X., Ergun, A., et al. (2009). MicroRNAs as modulators of smoking-induced gene expression changes in human airway epithelium. Proc. Natl. Acad. Sci. U.S.A. 106, 2319-2324. doi: 10.1073/pnas. 0806383106

Scholl, P. F., Musser, S. M., and Groopman, J. D. (1997). Synthesis and characterization of aflatoxin B1 mercapturic acids and their identification in rat urine. Chem. Res. Toxicol. 10, 1144-1151. doi: 10.1021/tx960161+

Shah, Y. M., Morimura, K., Yang, Q., Tanabe, T., Takagi, M., and Gonzalez, F. J. (2007). Peroxisome proliferator-activated receptor alpha regulates a microRNAmediated signaling cascade responsible for hepatocellular proliferation. Mol. Cell. Biol. 27, 4238-4247. doi: 10.1128/MCB.00317-07

Shigoka, M., Tsuchida, A., Matsudo, T., Nagakawa, Y., Saito, H., Suzuki, Y., et al. (2010). Deregulation of miR-92a expression is implicated in hepatocellular carcinoma development. Pathol. Int. 60, 351-357. doi: 10.1111/j.14401827.2010.02526.x

Shimada, T., Martin, M. V., Pruess-Schwartz, D., Marnett, L. J., and Guengerich, F. P. (1989). Roles of individual human cytochrome P-450 enzymes in the bioactivation of benzo(a)pyrene, 7,8-dihydroxy-7,8-dihydrobenzo(a)pyrene, and other dihydrodiol derivatives of polycyclic aromatic hydrocarbons. Cancer Res. 49, 6304-6312.

Singhal, A., Jayaraman, M., Dhanasekaran, D. N., and Kohli, V. (2012). Molecular and serum markers in hepatocellular carcinoma: predictive tools for prognosis and recurrence. Crit. Rev. Oncol. Hematol. 82, 116-140. doi: 10.1016/j.critrevonc.2011.05.005

Song, M. K., Park, Y. K., and Ryu, J. C. (2013). Polycyclic aromatic hydrocarbon (PAH)-mediated upregulation of hepatic microRNA-181 family promotes cancer cell migration by targeting MAPK phosphatase-5, regulating the activation of p38 MAPK. Toxicol. Appl. Pharmacol. 273, 130-139. doi: 10.1016/j.taap.2013.08.016

Strosnider, H., Azziz-Baumgartner, E., Banziger, M., Bhat, R. V., Breiman, R., Brune, M. N., et al. (2006). Workgroup report: public health strategies for reducing aflatoxin exposure in developing countries. Environ. Health Perspect. 114, 1898-1903. doi: 10.1289/ehp.9302

Su, H., Yang, J. R., Xu, T., Huang, J., Xu, L., Yuan, Y., et al. (2009). MicroRNA101, down-regulated in hepatocellular carcinoma, promotes apoptosis and suppresses tumorigenicity. Cancer Res. 69, 1135-1142. doi: 10.1158/00085472.CAN-08-2886

Sukata, T., Sumida, K., Kushida, M., Ogata, K., Miyata, K., Yabushita, S., et al. (2011). Circulating microRNAs, possible indicators of progress of rat hepatocarcinogenesis from early stages. Toxicol. Lett. 200, 46-52. doi: 10.1016/j.toxlet.2010.10.013

Sun, B., and Karin, M. (2013). Inflammation and liver tumorigenesis. Front. Med. 7, 242-254. doi: 10.1007/s11684-013-0256-4

Sun, Z., Han, Q., Zhou, N., Wang, S., Lu, S., Bai, C., et al. (2013). MicroRNA-9 enhances migration and invasion through KLF17 in hepatocellular carcinoma. Mol. Oncol. 7, 884-894. doi: 10.1016/j.molonc.2013.04.007

Szabo, G., Sarnow, P., and Bala, S. (2012). MicroRNA silencing and development of novel therapies for liver disease. J. Hepatol. 57, 462-466. doi: 10.1016/j.jhep.2012.01.030

Takagi, S., Nakajima, M., Mohri, T., and Yokoi, T. (2008). Post-transcriptional regulation of human pregnane $\mathrm{X}$ receptor by micro-RNA affects the 
expression of cytochrome P450 3A4. J. Biol. Chem. 283, 9674-9680. doi: 10.1074/jbc.M709382200

Takata, A., Otsuka, M., Kojima, K., Yoshikawa, T., Kishikawa, T., Yoshida, H., et al. (2011). MicroRNA-22 and microRNA-140 suppress NF-кB activity by regulating the expression of NF-кB coactivators. Biochem. Biophys. Res. Commun. 411, 826-831. doi: 10.1016/j.bbrc.2011.07.048

Taylor, E. L., and Gant, T. W. (2008). Emerging fundamental roles for non-coding RNA species in toxicology. Toxicology 246, 34-39. doi: 10.1016/j.tox.2007. 12.030

Tomimaru, Y., Eguchi, H., Nagano, H., Wada, H., Kobayashi, S., Marubashi, S., et al. (2012). Circulating microRNA-21 as a novel biomarker for hepatocellular carcinoma. J. Hepatol. 56, 167-175. doi: 10.1016/j.jhep.2011.04.026

Tsai, W. C., Hsu, P. W., Lai, T. C., Chau,.G. Y., Lin, C. W., Chen, C. M., et al. (2009). MicroRNA-122, a tumor suppressor microRNA that regulates intrahepatic metastasis of hepatocellular carcinoma. Hepatology 49, 1571-1582. doi: 10.1002/hep.22806

Tsai, W. C., Hsu, S. D., Hsu, C. S., Lai, T. C., Chen, S. J., Shen, R., et al. (2012). MicroRNA-122 plays a critical role in liver homeostasis and hepatocarcinogenesis. J. Clin. Invest. 122, 2884-2897. doi: 10.1172/JCI63455

Ueda, K. (2009). Effect of environmental chemicals on the genes and the gene expression. Yakugaku Zasshi 129, 1501-1506. doi: 10.1248/yakushi.129.1501

Ueng, Y. F., Shimada, T., Yamazaki, H., and Guengerich, F. P. (1995). Oxidation of aflatoxin B1 by bacterial recombinant human cytochrome $\mathrm{P} 450$ enzymes. Chem. Res. Toxicol. 8, 218-225. doi: 10.1021/tx00044a006

Ura, S., Honda, M., Yamashita, T., Ueda, T., Takatori, H., Nishino, R., et al. (2009). Differential microRNA expression between hepatitis B and hepatitis C leading disease progression to hepatocellular carcinoma. Hepatology 49, 1098-1112. doi: 10.1002/hep. 22749

Vaira, V., Faversani, A., Dohi, T., Montorsi, M., Augello, C., Gatti, S., et al. (2012). miR-296 regulation of a cell polarity-cell plasticity module controls tumor progression. Oncogene 31, 27-38. doi: 10.1038/onc.2011.209

Valencia-Quintana, R., Sánchez-Alarcón, J., Tenorio, M. G., Deng, Y., Waliszewski, S. M., and Valera, M. A. (2012). Preventive strategies aimed at reducing the health risks of Aflatoxin B1. Toxicol. Environ. Health Sci. 4, 71-79. doi: 10.1007/s13530-012-0119-4

Varnholt, H., Drebber, U., Schulze, F., Wedemeyer, I., Schirmacher, P., Dienes, H. P., et al. (2008). microRNA gene expression profile of hepatitis $C$ virus-associated hepatocellular carcinoma. Hepatology 47, 1223-1232. doi: 10.1002/hep. 22158

Volinia, S., Calin, G. A., Liu, C. G., Ambs, S., Cimmino, A., Petrocca, F., et al. (2006). A microRNA expression signature of human solid tumors defines cancer gene targets. Proc. Natl. Acad. Sci. U.S.A. 103, 2257-2261. doi: 10.1073/pnas.0510565103

Vuppalanchi, R., Liang, T., Goswami, C. P., Nalamasu, R., Li, L., Jones, D., et al. (2013). Relationship between differential hepatic microRNA expression and decreased hepatic cytochrome P450 3A activity in cirrhosis. PLoS ONE 8:e74471. doi: 10.1371/journal.pone.0074471

Wang, B., Hsu, S. H., Majumder, S., Kutay, H., Huang, W., Jacob, S. T., et al. (2010). TGFbeta-mediated upregulation of hepatic miR-181b promotes hepatocarcinogenesis by targeting TIMP3. Oncogene 29, 1787-1797. doi: 10.1038/onc. 2009.468

Wang, B., Majumder, S., Nuovo, G., Kutay, H., Volinia, S., Patel, T., et al. (2009b). Role of microRNA-155 at early stages of hepatocarcinogenesis induced by choline-deficient and amino acid-defined diet in C57BL/6 mice. Hepatology 50, 1152-1161. doi: 10.1002/hep.23100

Wang, C. M., Wang, Y., Fan, C. G., Xu, F. F., Sun, W. S., Liu, Y. G., et al. (2011). miR-29c targets TNFAIP3, inhibits cell proliferation and induces apoptosis in hepatitis B virus-related hepatocellular carcinoma. Biochem. Biophys. Res. Commun. 411, 586-592. doi: 10.1016/j.bbrc.2011.06.191

Wang, J., Li, J., Shen, J., Wang, C., Yang, L., and Zhang, X. (2012b). MicroRNA182 downregulates metastasis suppressor 1 and contributes to metastasis of hepatocellular carcinoma. BMC Cancer 12:227. doi: 10.1186/1471-2407-12-227

Wang, J., Li, J., Wang, X., Zheng, C., and Ma, W. (2013). Downregulation of microRNA-214 and overexpression of FGFR-1 contribute to hepatocellular carcinoma metastasis. Biochem. Biophys. Res. Commun. 439, 47-53. doi: 10.1016/j.bbrc.2013.08.032

Wang, K., Zhang, S., Marzolf, B., Troisch, P., Brightman, A., Hu, Z., et al. (2009a). Circulating microRNAs, potential biomarkers for drug-induced liver injury. Proc. Natl. Acad. Sci. U.S.A. 106, 4402-4407. doi: 10.1073/pnas.0813371106
Wang, X. W., Heegaard, N. H. H., and Ørum, H. (2012a). microRNAs in liver disease. Gastroenterology 142, 1431-1443. doi: 10.1053/j.gastro.2012.04.007

Wang, Y., Lee, A. T., Ma, J. Z., Wang, J., Ren, J., Yang, Y., et al. (2008). Profiling microRNA expression in hepatocellular carcinoma reveals microRNA-224 upregulation and apoptosis inhibitor-5 as a microRNA-224-specific target. J. Biol. Chem. 283, 13205-13215. doi: 10.1074/jbc.M707629200

Wei, L., Gong, X., Martinez, O. M., and Krams, S. M. (2013a). Differential expression and functions of microRNAs in liver transplantation and potential use as non-invasive biomarkers. Transpl. Immunol. 29, 123-129. doi: 10.1016/j.trim.2013.08.005

Wei, R., Huang, G. L., Zhang, M. Y., Li, B. K., Zhang, H. Z., Shi, M., et al. (2013b). Clinical significance and prognostic value of microRNA expression signatures in hepatocellular carcinoma. Clin. Cancer Res. 19, 4780-4791. doi: 10.1158/10780432.CCR-12-2728

Wild, C. P. (2009). Environmental exposure measurement in cancer epidemiology. Mutagenesis 24, 117-125. doi: 10.1093/mutage/gen061

Wild, C. P., and Turner, P. C. (2002). The toxicology of aflatoxins as a basis for public health decisions. Mutagenesis 17, 471-481. doi: 10.1093/mutage/17.6.471

Wong, K. F., Xu, Z., Chen, J., Lee, N. P., and Luk, J. M. (2013). Circulating markers for prognosis of hepatocellular carcinoma. Expert Opin. Med. Diagn. 7, 319-329. doi: 10.1517/17530059.2013. 795146

Wong, Q. W., Ching, A. K., Chan, A. W., Choy, K. W., To, K. F., Lai, P. B., et al. (2010). MiR-222 overexpression confers cell migratory advantages in hepatocellular carcinoma through enhancing AKT signaling. Clin. Cancer Res. 16, 867-875. doi: 10.1158/1078-0432.CCR-09-1840

Wong, Q. W., Lung, R. W., Law, P. T., Lai, P. B., Chan, K. Y., To, K. F., et al. (2008). MicroRNA-223 is commonly repressed in hepatocellular carcinoma and potentiates expression of Stathmin 1. Gastroenterology 135, 257-269. doi: 10.1053/j.gastro.2008.04. 003

Wu, N., Liu, X., Xu, X., Fan, X., Liu, M., Li, X., et al. (2011). MicroRNA-373, a new regulator of protein phosphatase 6 , functions as an oncogene in hepatocellular carcinoma. FEBS J. 278, 2044-2054. doi: 10.1111/j.1742-4658.2011.08120.x

Xia, Q., Huang, X.-Y., Xue, F., Zhang, J.-J., Zhai, B., Kong, D.-C., et al. (2013). "Genetic polymorphisms of DNA repair genes and DNA repair capacity related to aflatoxin B1 (AFB1)-induced DNA damages," in New Research Directions in DNA Repair, Chapter 15, 1st Edn., ed C. Chen (Rijeka: InTech), 377-412. doi: $10.5772 / 53967$

Xie, Q. H., He, X. X., Chang, Y., Sun, S. Z., Jiang, X., Li, P. Y., et al. (2011). MiR-192 inhibits nucleotide excision repair by targeting ERCC3 and ERCC4 in HepG2.2.15 cells. Biochem. Biophys. Res. Commun. 410, 440-445. doi: 10.1016/j.bbrc.2011.05.153

Xiong, Y., Fang, J. H., Yun, J. P., Yang, J., Zhang, Y., Jia, W. H., et al. (2010). Effects of microRNA-29 on apoptosis, tumorigenicity, and prognosis of hepatocellular carcinoma. Hepatology 51, 836-845. doi: 10.1002/hep.23380

Xu, J., Wu, C., Che, X., Wang, L., Yu, D., Zhang, T., et al. (2011). Circulating microRNAs, miR-21, miR-122, and miR-223, in patients with hepatocellular carcinoma or chronic hepatitis. Mol. Carcinog. 50, 136-142. doi: $10.1002 / \mathrm{mc} .20712$

Xu, J., Zhu, X., Wu, L., Yang, R., Yang, Z., Wang, Q., et al. (2012). MicroRNA-122 suppresses cell proliferation and induces cell apoptosis in hepatocellular carcinoma by directly targeting Wnt/ $\beta$-catenin pathway. Liver Int. 32, 752-760. doi: 10.1111/j.1478-3231.2011.02750.x

Xu, T., Zhu, Y., Wei, Q. K., Yuan, Y., Zhou, F., Ge, Y. Y., et al. (2008). A functional polymorphism in the miR-146a gene is associated with the risk for hepatocellular carcinoma. Carcinogenesis 29, 2126-2131. doi: 10.1093/carcin/bgn195

Xu, T., Zhu, Y., Xiong, Y., Ge, Y. Y., Yun, J. P., and Zhuang, S. M. (2009). MicroRNA195 suppresses tumorigenicity and regulates G1/S transition of human hepatocellular carcinoma cells. Hepatology 50, 113-121. doi: 10.1002/hep.22919

Xu, Y., Xie, Y., Wang, X., Chen, X., Liu, Q., Ying, M., et al. (2013). Identification of cancer stem cells from hepatocellular carcinoma cell lines and their related microRNAs. Oncol. Rep. 30, 2056-2062. doi: 10.3892/or.2013.2703

Yamamoto, Y., Kosaka, N., Tanaka, M., Koizumi, F., Kanai, Y., Mizutani, T., et al. (2009). MicroRNA-500 as a potential diagnostic marker for hepatocellular carcinoma. Biomarkers 14, 529-538. doi: 10.3109/13547500903150771

Yan, D., Ng, W. L., Zhang, X., Wang, P., Zhang, Z., Mo, Y. Y., et al. (2010). Targeting DNA-PKcs and ATM with miR-101 sensitizes tumors to radiation. PLoS ONE 5:e11397. doi: 10.1371/journal.pone.0011397

Yang, F., Yin, Y., Wang, F., Wang, Y., Zhang, L., Tang, Y., et al. (2010). miR-17-5p promotes migration of human hepatocellular carcinoma cells through the p38 
mitogen-activated protein kinase-heat shock protein 27 pathway. Hepatology 51 , 1614-1623. doi: 10.1002/hep.23566

Ying, Q., Liang, L., Guo, W., Zha, R., Tian, Q., Huang, S., et al. (2011). Hypoxiainducible microRNA-210 augments the metastatic potential of tumor cells by targeting vacuole membrane protein 1 in hepatocellular carcinoma. Hepatology 54, 2064-2075. doi: 10.1002/hep.24614

Yokoi, T., and Nakajima, M. (2011). Toxicological implications of modulation of gene expression by microRNAs. Toxicol. Sci. 123, 1-14. doi: $10.1093 /$ toxsci/kfr 168

Yoon, S., Kim, T. H., Natarajan, A., Wang, S. S., Choi, J., Wu, J., et al. (2010). Acute liver injury upregulates microRNA-491-5p in mice, and its overexpression sensitizes Hep G2 cells for tumour necrosis factor-alpha-induced apoptosis. Liver Int. 30, 376-387. doi: 10.1111/j.1478-3231.2009.02181.x

Yoon, S. O., Chun, S. M., Han, E. H., Choi, J., Jang, S. J., Koh, S. A., et al. (2011). Deregulated expression of microRNA-221 with the potential for prognostic biomarkers in surgically resected hepatocellular carcinoma. Hum. Pathol. 42, 1391-1400. doi: 10.1016/j.humpath.2010.12.010

Zhang, B., and Pan, X. (2009). RDX induces aberrant expression of microRNAs in mouse brain and liver. Environ. Health Perspect. 117, 231-240. doi: $10.1289 / \mathrm{ehp} .11841$

Zhang, J., Luo, N., Luo, Y., Peng, Z., Zhang, T., and Li, S. (2012). microRNA150 inhibits human CD133-positive liver cancer stem cells through negative regulation of the transcription factor c-Myb. Int. J. Oncol. 40, 747-756. doi: 10.3892/ijo.2011.1242

Zhang, J. F., He, M. L., Fu, W. M., Wang, H., Chen, L. Z., Zhu, X., et al. (2011). Primate-specific microRNA-637 inhibits tumorigenesis in hepatocellular carcinoma by disrupting signal transducer and activator of transcription 3 signaling. Hepatology 54, 2137-2148. doi: 10.1002/hep.24595

Zhang, X., Liu, S., Hu, T., He, Y., and Sun, S. (2009). Up-regulated microRNA143 transcribed by nuclear factor kappa B enhances hepatocarcinoma metastasis by repressing fibronectin expression. Hepatology 50, 490-499. doi: 10.1002/hep.23008

Zheng, F., Liao, Y. J., Cai, M. Y., Liu, Y. H., Liu, T. H., Chen, S. P., et al. (2012a). The putative tumour suppressor microRNA-124 modulates hepatocellular carcinoma cell aggressiveness by repressing ROCK2 and EZH2. Gut 61, 278-289. doi: $10.1136 /$ gut.2011.239145
Zheng, J., Dong, P., Gao, S., Wang, N., and Yu, F. (2013). High expression of serum miR-17-5p associated with poor prognosis in patients with hepatocellular carcinoma. Hepatogastroenterology 60, 549-552.

Zheng, Y., Yin, L., Chen, H., Yang, S., Pan, C., Lu, S., et al. (2012b). miR-376a suppresses proliferation and induces apoptosis in hepatocellular carcinoma. FEBS Lett. 586, 2396-2403. doi: 10.1016/j.febslet.2012.05.054

Zhi, Q., Zhu, J., Guo, X., He, S., Xue, X., Zhou, J., et al. (2013). Metastasisrelated miR-185 is a potential prognostic biomarker for hepatocellular carcinoma in early stage. Biomed. Pharmacother. 67, 393-398. doi: 10.1016/j.biopha.2013.03.022

Zhou, Y. M., Cao, L., Li, B., Zhang, R. X., Sui, C. J., Yin, Z. F., et al. (2012). Clinicopathological significance of ZEB1 protein in patients with hepatocellular carcinoma. Ann. Surg. Oncol. 19, 1700-1706. doi: 10.1245/s10434-011$1772-6$

Conflict of Interest Statement: The authors declare that the research was conducted in the absence of any commercial or financial relationships that could be construed as a potential conflict of interest.

Received: 20 December 2013; paper pending published: 08 January 2014; accepted: 26 February 2014; published online: 18 March 2014.

Citation: Valencia-Quintana R, Sánchez-Alarcón J, Tenorio-Arvide MG, Deng Y, Montiel-González JMR, Gómez-Arroyo S, Villalobos-Pietrini R, Cortés-Eslava J, Flores-Márquez AR and Arenas-Huertero F (2014) The microRNAs as potential biomarkers for predicting the onset of aflatoxin exposure in human beings: a review. Front. Microbiol. 5:102. doi: 10.3389/fmicb.2014.00102

This article was submitted to Food Microbiology, a section of the journal Frontiers in Microbiology.

Copyright (c) 2014 Valencia-Quintana, Sánchez-Alarcón, Tenorio-Arvide, Deng, Montiel-González, Gómez-Arroyo, Villalobos-Pietrini, Cortés-Eslava, Flores-Márquez and Arenas-Huertero. This is an open-access article distributed under the terms of the Creative Commons Attribution License (CC BY). The use, distribution or reproduction in other forums is permitted, provided the original author(s) or licensor are credited and that the original publication in this journal is cited, in accordance with accepted academic practice. No use, distribution or reproduction is permitted which does not comply with these terms. 